\title{
Does Partisan Identity Reduce Support for Electoral Fairness?
}

\author{
Matthew H. Graham*
}

March 23, 2021

3,922 words

\begin{abstract}
Despite strong theoretical reasons to expect an inverse relationship between strength of partisan identity and support for electoral fairness, little empirical evidence exists on this question. This paper analyzes two studies that implement a twin experimental approach to examining this relationship. In a candidate choice experiment, a one standard deviation increase in partisan social identity predicts about a 10 percent smaller penalty for violations of electoral fairness, with similar results in both studies. In Study 1 , a randomly-assigned partisan identity priming treatment yields a similar relationship on a smaller scale, with an 0.1 standard deviation boost in identity producing about a 1 percent increase in support for anti-fairness candidates. In Study 2, the priming treatment fails to move identity and yields no corresponding change in support for electoral fairness. These results provide suggestive evidence on the relationship between partisanship and support for democratic values while highlighting lessons for future research.
\end{abstract}

${ }^{*}$ Postdoctoral Research Scientist, Institute for Data, Democracy, and Politics, George Washington University. mattgraham@gwu. edu. For helpful comments on earlier versions of this work, I thank Peter Aronow, Alex Coppock, Greg Huber, Kyle Peyton, Lilla Orr, Irina Soboleva, Milan Svolik, and seminar participants at Yale and the Southern Political Science Association. Study 1 was funded by two Yale entities, the Institution for Social and Policy Studies (ISPS) and the Center for the Study of American Politics (CSAP). Study 2 was funded by Time Sharing Experiments in the Social Sciences (TESS, grant number 1155). The Yale Institutional Review Board approved the study design (application number 2000025465). Preregistrations for both studies are available through the Open Science Framework (OSF, numbers sxdbh and gdpk7). 
Whereas coups were once the greatest threat to the stability of democratic governments, recent cases of democratic decline generally involve elected leaders who wish to minimize threats to their hold on power (Svolik 2015). By tilting the electoral playing field in their favor, elected autocrats can maintain the trappings of democracy while muting or even eliminating electoral accountability (Schedler 2002; Levitsky and Way 2010; Bermeo 2016). The existence of tradeoffs between partisanship and electoral fairness challenge traditional measures of support for democracy, which peak among strong partisans and ideological extremists (Appendix A.3). At the ballot box, punishing candidates for violating standards of electoral fairness requires voting against one's preferred party in response to an action that gives that party an electoral advantage (Svolik 2020). This suggests that in electoral choices, partisanship should reduce support for electoral fairness (Graham and Svolik 2020).

This paper presents experimental evidence on the relationship between partisan identity and support for electoral fairness. The analysis first examines how randomly assigned violations of electoral fairness affect support for hypothetical candidates. The violations, ranging from subtle ("party line changes" to voting rules) to severe (systematic absentee ballot fraud), were all committe by real U.S. politicians between 2010 and 2018. In two separate studies, the electoral penalty for such violations is smaller among respondents with stronger partisan identities. A one standard deviation increase in partisan social identity, as measured by a state-of-the-art scale based on Huddy et al. (2015) and Greene (1999), predicts about a 10 percent decline in the penalty for candidates who undermine electoral fairness for partisan gain.

In an attempt to gain causal leverage on partisan identity itself, the design next turns to priming treatements. Priming treatments aim to temporarily raise the salience of certain considerations in the respondent's mind, making subsequent responses more-influenced by those considerations than they would be at baseline (Iyengar et al. 1984; Krosnick and Kinder 1990). In recent years, scholars have increasingly used priming treatments to study causal effects of political and social identities (Hutchings and Jardina 2009; Jackson 2011; Klar 
2013; Levendusky 2017). This strategy is well-suited to the task of examining the effects of partisan identity, whose status as a fully-formed, stable attitude (Ansolabehere et al. 2008; Campbell et al. 1960; Green and Palmquist 1994) generally stands in the way of attempts to study its causal effect (but see Gerber et al. 2010).

The priming treatments yield mixed results. In the first study, an 0.1 standard deviation increase in partisan identity is found to result in about 1 percentage point greater support for copartisan candidates who undermine electoral fairness. However, the second study fails to produce a statistically detectable effect on partisan identity. Even as this fails to support the motivating hypotheses, this failure at the manipulation check stage leaves the experiment equally unable to rule a relationship out. This leaves the priming experiments to provide only weak, suggestive evidence that partisan identity reduces support for electoral fairness.

Even as these results are among the first direct evidence of an inverse relationship between Americans' partisan social identities and support for electoral fairness, this investigation ultimately fails to prove decisively that this relationship is causal. The approach and its mixed results contain lessons as to the strengths and limitations of experimental designs that aim to estimate the causal effect of partisan identity, as well as the design of candidate choice experiments more generally. This includes a novel, design-based approach to fixing parameters in (statistically) exchangeable candidate choices, which allows the design of Study 2 transcend a tradeoff between survey space, sample size, and the desire to replicate Study 1's candidate choice experiment while allocating maximal statistical power to the priming treatment.

\section{Data}

This paper analyzes two implementations of the same research design, a full implementation (Study 1) and partial implementation in a higher-quality sample (Study 2). Study 1 
was fielded to 6,997 respondents in August-September 2019. ${ }^{1}$ Respondents were recruited online using Lucid using quotas that match Census demographic benchmarks. To improve the sample's representativeness, raked weights were calculated based on the American Community Survey's one-year estimates using the survey package in R. A brief pre-registration specified the core hypotheses and indicated the intent to use one-sided tests.

Study 2 was fielded to 4,027 respondents in November 2019-January 2020. Respondents were drawn from the AmeriSpeak panel, which is maintained by the National Opinion Research Center (NORC). Participants are initially recruited based on their address, then sampled into individual studies. Estimates are weighted using vendor-provided weights. A pre-analysis plan specified one-sided tests and indicated that the covariate-adjusted estimator proposed by Lin (2013) would be favored in all analysis. Differences between Studies 1 and 2 are discussed below and are justified in detail in Appendix B.

\section{Candidate Choice Experiment}

In the full implementation of the research design (Study 1), each respondent completed twelve candidate choice tasks. In each task, candidate 1 was predesignated as a copartisan, anti-fairness candidate, while candidate 2 was predesignated to be a pro-fairness candidate who either criticized the anti-fairness action ("critic") or proposed a concrete reform aimed at preventing such actions in the future ("reformer"). ${ }^{2}$ Block random assignment determined in which of these six choices the electoral fairness positions would be revealed to the respondent, providing causal leverage of the effect of the electoral fairness positions on support for candidate 1. Using the six-point scale depicted in Figure 1, this can be calculated in one of two ways: by assigning numerical probabilities to each scale point, or by collapsing the scale into an indicator variable.

\footnotetext{
${ }^{1}$ Consistent with the pre-registration document, 3,700 respondents were ordered. In a fortunate accident, many more were routed to the survey.

${ }^{2}$ The decision to pit pro- and anti-fairness candidates against one another was informed by a simple model of the anticipated treatment effects, which suggests that the effect of partisan identity will be easier to detect when the difference between the two candidates' electoral fairness positions is larger (Appendix B.1). This important in light of the difficulty of priming partisan identity.
} 
Figure 1: Example candidate choice, Study 1.

\begin{tabular}{cc} 
Rosa Perez & Ebony Mosley \\
\hline \multicolumn{1}{c}{ Democrat } & Democrat \\
Latina woman \\
40 years old & Black woman \\
\hline $\begin{array}{c}\text { During the last election, Perez encouraged } \\
\text { local Democratic officials to make "party } \\
\text { line changes" to voting times and }\end{array}$ & $\begin{array}{c}\text { Proposed putting an independent agency } \\
\text { in charge of overseeing all elections } \\
\text { locations. }\end{array}$ \\
$\begin{array}{c}\text { Supports cracking down on employers who } \\
\text { knowingly hire and exploit illegal } \\
\text { immigrants. }\end{array}$ & $\begin{array}{c}\text { Supports reducing the length of } \\
\text { prescription drug patents so generics } \\
\text { become available sooner. }\end{array}$ \\
\hline
\end{tabular}

Which candidate do you prefer?

\begin{tabular}{|c|c|c|c|c|c|}
\hline $\begin{array}{c}\text { Definitely } \\
\text { Perez }\end{array}$ & $\begin{array}{c}\text { Probably } \\
\text { Perez }\end{array}$ & $\begin{array}{l}\text { Maybe } \\
\text { Perez }\end{array}$ & $\begin{array}{l}\text { Maybe } \\
\text { Mosley }\end{array}$ & $\begin{array}{c}\text { Probably } \\
\text { Mosley }\end{array}$ & $\begin{array}{c}\text { Definitely } \\
\text { Mosley }\end{array}$ \\
\hline
\end{tabular}

Random assignment determined the candidates' characteristics. In six choices, candidate 2 was the respondent's coparitsan. In the other six, candidate 2 was of the opposite party. Accordingly, each respondent completed exactly three tasks of the following types:

- Neutral, same-party opponent. Both candidates were the respondent's co-partisans. No systematic differences existed between the two candidates.

- Neutral, opposite-party opponent. Candidate 1 was the respondent's co-partisan and candidate 2 was of the opposite party. No other systematic differences existed between the two candidates.

- Anti-fairness, same-party opponent. Both candidates were the respondent's copartisans. Candidate 1 was described as having taken an action that undermined electoral fairness. Candidate 2 either a critic or a reformer. No other systematic differences existed between the two candidates.

- Anti-fairness, opposite party opponent. Candidate 1 was the respondent's copartisan. Candidate 2 was of the opposite party and was either a critic or a reformer. No other systematic differences existed between the two candidates.

Table 1 lists the full text of the electoral fairness positions. Each violation of electoral fairness was committed by at least one American politician between 2010 and 2018. The 
remaining attributes - age, gender, race, name, policy positions, and appearance on the left or right of the choice table - were assigned to each candidate with equal probability. For more information, see Appendix B.

Prior to the candidate choice experiment, a randomly selected subset of respondents (simple random assignment, $p=0.5$ ) completed a task designed to prime partisan identity. This task is described in detail below; in this section, only the control group is analyzed, preserving the baseline relationship between partisan identity and the effect of the electoral fairness positions on candidate choice. Next, all respondents completed a five-item partisan social identity scale based on Huddy, Mason and Aaroe (2015) and Greene (1999). The scale was converted into an standardized index by subtracting the control mean and dividing by the control standard deviation.

Whereas Study 1 was fielded in a setting that easily accommodated the full design, Study 2 was supported by a grant that imposes a tradeoff between survey length and sample size. Based on a model of the treatment effects and a power analysis (Appendix B.1 and B.2), the following design changes were made. First, Study 2 included only anti-fairness candidates with copartisan, reformist opponents. Focusing on copartisan matchups eases the interpretation of the priming treatment, which could boost support for copartisan candidates independently of its effect on support for electoral fairness. Second, in response to a grant reviewer's request for additional attributes, each candidate was randomly assigned a marital status, a number of children, and a profession. In a corresponding move, race and gender were left to be inferred from the candidates' names, which in both studies were randomly selected from a list of names that send clear race and gender signals (Butler and Homola 2017). Third, to accommodate third-party programmers, respondent preferences were measured as a binary choice rather than the quasi-continuous scale depicted in Figure 1.

\section{Fixing the Baseline}

To deal with the constraints imposed by Study 2, the analysis in this section makes a design-based assumption about average support for candidate 1 in neutral, same-party 
Table 1: Electoral fairness positions.

Unfair action (real-world link) Critic's response Reformer's response

1. During the last election, one of [last name]'s staff collected blank absentee ballots from voters and filled them in. (Mark Harris)

2. As [his/her] state's secretary of state, hired a consultant to encourage counties to close polling places in areas that tend to support [other party]s. (Brian Kemp)

3. Refused to resign as the state secretary of state, which placed [him/her] in charge of overseeing the election. (Brian Kemp)

4. During the last election, [last name] encouraged local [own party] officials to make "party line changes" to voting times and locations. (Dallas Woodhouse)

5. Admitted that $[\mathrm{s} / \mathrm{he}]$ had only supported a new electoral map because it helped [own]s win extra seats in Congress. (Martin O'Malley)

6. After the state supreme court blocked an electoral map that would have helped [own party]s, [last name] voted to impeach all the [other party] judges. (Pennsylvania legislature)
Criticized [last name] for hiring the staff member, saying [he/she] should have exercised better judgment.

Criticized [last name] for hiring the consultant, saying [he/she] should have exercised better judgment.

Called on [last name] to resign as state secretary of state, saying that nobody should supervise their own election.

Criticized [last name] for attempting to manipulate the voting system for partisan gain.

Criticized [last name] for supporting an unfair electoral map.

Criticized [last name] for supporting the plan to impeach judges in retaliation for their position on redistricting.
Supported a new campaign to make sure absentee voters know never to give their ballot to anyone else.

Proposed putting an independent agency in charge of overseeing all elections conducted in the state.

Proposed a bill requiring future secretaries of state to recuse themselves from overseeing their own elections.

Proposed putting an independent agency in charge of overseeing all elections conducted in the state.

Proposed giving the power to draw electoral maps to an independent commission that is required to meet standards of fairness.

Proposed giving the power to draw electoral maps to an independent commission that is required to meet standards of fairness.

Note: Kemp and Woodhouse made public statements opposing Donald Trump's effort to overturn the results of the 2020 presidential election. 
matchups. This transcends a key tradeoff imposed by limited survey space, allowing maximum statistical power to be allocated to the priming treatment analyzed in the next section.

Note that under the research design, candidate choices that pit two neutral copartisans have no systematic differences in attributes between candidates 1 and 2. Every characteristic is assigned to both candidates with equal probability, meaning that the two sets of candidate attributes are exchangeable (Hoff 2009). Consequently, the effect of revealing the electoral fairness positions in copartisan matchups can be estimated without the inclusion of an explicit comparison group. To see this, let $X$ be partisan identity, $Y$ be support for the anti-fairness candidate, and $D$ be an indicator variable for whether the fairness positions are revealed (1) or hidden (0). The conditional average treatment effect (CATE) of revealing the electoral fairness position is

$$
\mathbb{E}\left[Y_{i} \mid D_{i}=1, X=x\right]-\mathbb{E}\left[Y_{i} \mid D_{i}=0, X=x\right]
$$

Appendix C.1 proves that under exchangeability, $\mathbb{E}\left[Y_{i} \mid D_{i}=0, X=x\right]=0.5$. Under this fixed baseline assumption, the CATE can be estimated by

$$
\begin{aligned}
& \mathbb{E}\left[Y_{i} \mid D_{i}=1, X=x\right]-0.5 \\
= & \mathbb{E}\left[Y_{i}-0.5 \mid D_{i}=1, X=x\right] .
\end{aligned}
$$

This allows Study 2 to replicate Study 1's results for same-party matchups without including any neutral matchups. The upside of this tradeoff is realized the next section, wherein the small expected effect of the identity prime made it advantageous to maximize the number of anti-fairness candidates evaluated by each respondent. ${ }^{3}$

\footnotetext{
${ }^{3}$ For further discussion, see the power analysis in Appendix B.2.
} 


\section{Results}

Figure 2 plots the conditional expectation of support for candidate 1 separately for neutral candidates $\left(\mathbb{E}\left[Y_{i} \mid D_{i}=0, X=x\right]\right.$, solid black lines) and anti-fairness candidates $\left(\mathbb{E}\left[Y_{i} \mid D_{i}=1, X=x\right]\right.$, dashed red lines). The thick lines are semi-parametric smoothed lines, while the thin lines with error bars are linear approximations. In the left and middle panels, the two lines converge slightly, indicating that as partisan identity increases, the penalty for anti-fairness candidates shrinks. In the middle panel, the solid line for neutral candidates is completely flat, providing empirical evidence that the baseline is fixed. In the right panel, support for anti-fairness candidates also rises slightly with partisan identity, similar to study 1.

Figure 2: Candidate support by partisan identity.
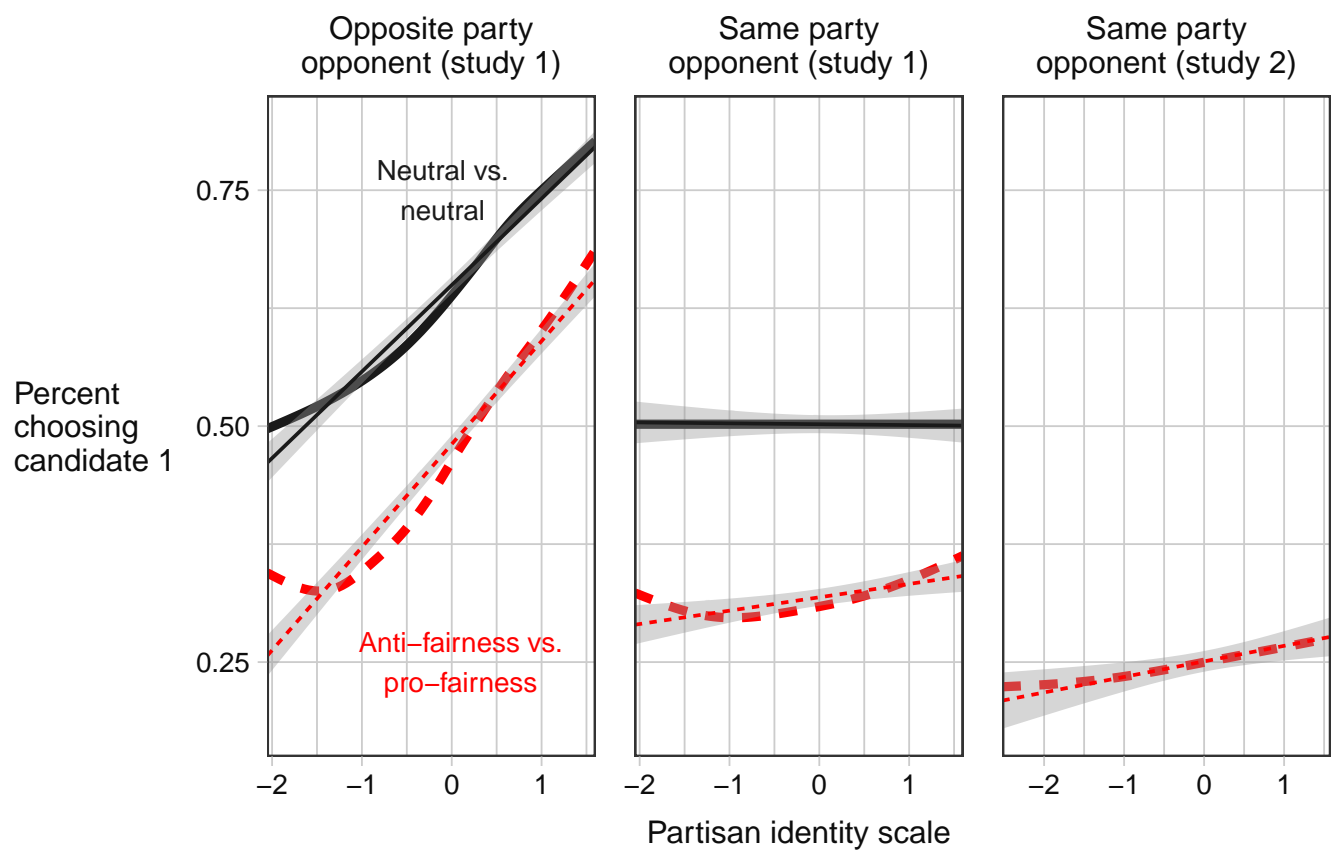

Note: Figure displays the CEF by treatment group using a smoothed line (thick) and a linear approximation (thin). Solid lines represent choices between neutral candidates. Dashed red lines represent choices between anti- and pro-fairness candidates. Differences between pairs of lines are estimates of (1). The distribution of partisan identity (x-axis) is displayed in Figure 3. 
The close correspondence between the smoothed lines and linear approximations ${ }^{4}$ in Figure 2 justifies the use of a standard linear, treatment by covariate model to summarize the treatment effect heterogeneity (Hainmueller et al. 2019). ${ }^{5}$ The model is

$$
Y_{i}=\alpha+\beta_{1} X_{i}+\beta_{2} D_{i}+\beta_{3} D_{i} X_{i}+\epsilon_{i},
$$

where all terms are defined above. Appendix C.2 proves that with a fixed baseline, $\beta_{2}$ and $\beta_{3}$ can be estimated using only data from the treatment group.

Table 2 presents OLS estimates of the parameters in (3), with standard errors clustered by respondent. The estimates in the left column pertain to Study 1 anti-fairness candidates facing opposite-party opponents. Such candidates faced a penalty of 17 percentage points among respondents with an average level of partisan social identity (which is set to zero by standardization). A one standard deviation increase in partisan identity predicts about 2.5 percentage point smaller penalty. The predicted penalty for a respondent at the 90th percentile of the partisan identity distribution is 31 percent smaller than the predicted effect at the 10 th percentile. ${ }^{6}$

The remaining columns of Table 2 pertain to anti-fairness candidates facing a sameparty opponents. Anti-fairness candidates faced a penalty of about 18 percentage points at the average level of partisan identity in Study 1 and about 23 percentage points in Study 2. The middle two columns of Table 2 pertain to Study 1. The center-left column refrains from making the fixed baseline assumption, while the center-right column makes it. Consistent with the proof in Appendix C.2, the estimates of $\beta_{2}$ and $\beta_{3}$ are quite similar, differing only due to sampling error in the empirical estimates of $\beta_{0}$ and $\beta_{1}$. The rightmost column

\footnotetext{
${ }^{4}$ Note that in the region with the weakest correspondence between the smoothed line and linear approximation, -2 to -1.5 on the partisan identity scale, there are very little data (see distributions in Figure 3 ). To safeguard against misleading estimates based on linear extrapolation, the text reports predicted values for the 10th and 90th percentiles of partisan identity, which are -1.32 and 1.31 in both studies.

${ }^{5}$ The second key assumption highlighted by Hainmueller et al. (2019), common support, holds by design in randomized experiments.

${ }^{6}$ Calculation: $1-\frac{\hat{\beta}_{2}+1.32 \times \beta_{3}}{\hat{\beta}_{2}-1.31 \times \beta_{3}}=1-\frac{14.2}{20.7}=0.31$.
} 
Table 2: Treatment effect heterogeneity, electoral fairness contrast.

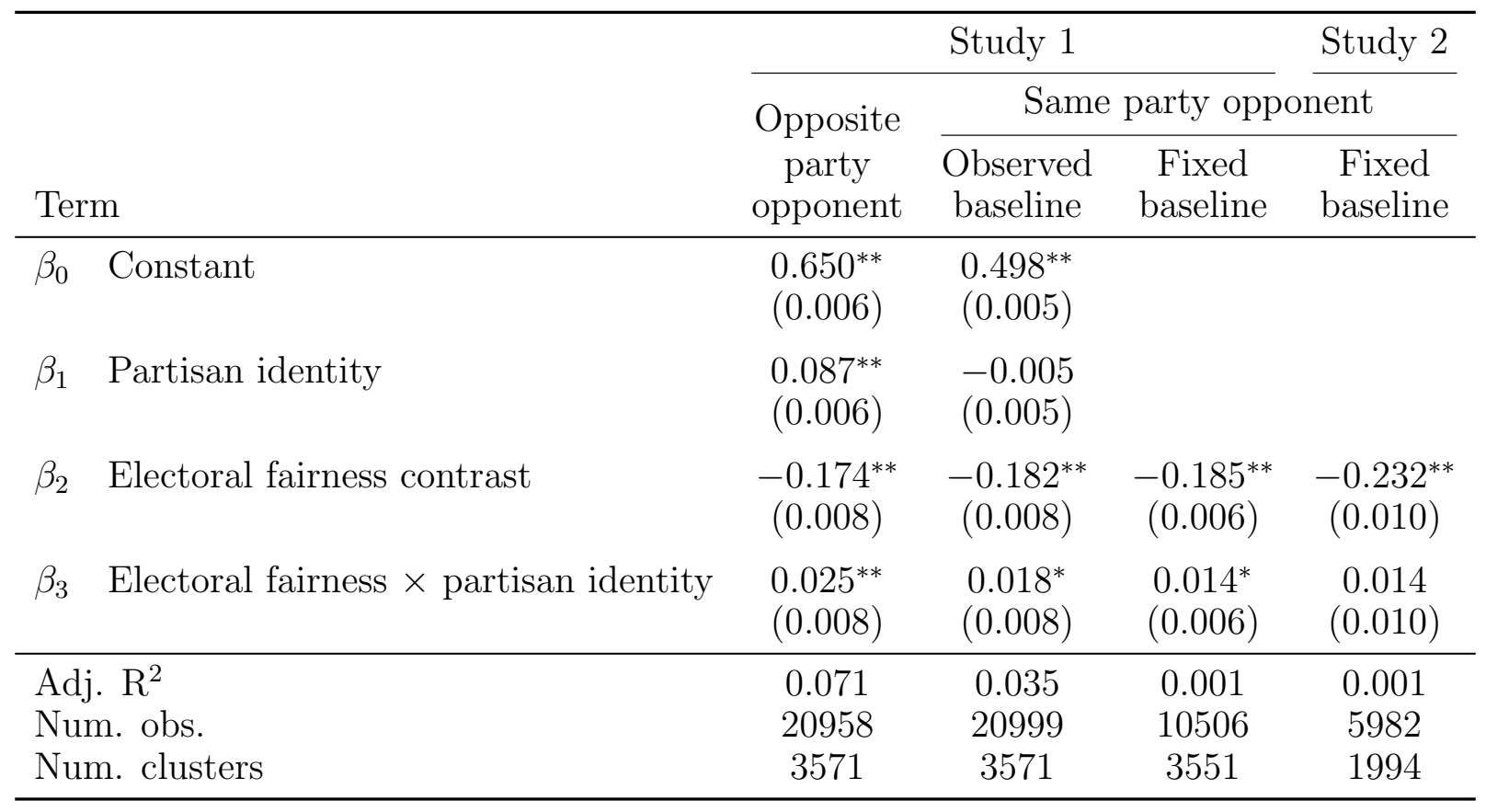

Note: Table presents estimates of the parameters in (4). Standard errors clustered by respondent.

replicates this result for Study 2. The estimate of treatment effect heterogeneity given by $\beta_{3}$ is quite similar in magnitude, but narrowly misses statistical significance. Relative to the 10th percentile of partisan identity, the predicted effect at the 90 th percentile is 18 percent smaller in study 1 and 15 percent smaller in study $2 .{ }^{7}$

These results suggest that relative to weaker partisans, stronger partisans are lesspenalizing violations of electoral fairness. However, it does not establish that identity itself causes these differences.

\section{Priming Experiment}

The priming treatment prompted respondents to think of partisanship as being aligned with their other social identities. This targets a key mechanism highlighted in accounts of partisanship as a social identity (Mason 2018) and closely relates to the emphasis in comparative research on the importance of cross-cutting social cleavages for democratic stability

${ }^{7}$ Study 1: $1-\frac{\hat{\beta}_{2}+1.32 \times \hat{\beta}_{3}}{\hat{\beta}_{2}-1.31 \times \hat{\beta}_{3}}=1-\frac{16.7}{20.3}=0.18$. Study $2: 1-\frac{\hat{\beta}_{2}+1.32 \times \hat{\beta}_{3}}{\hat{\beta}_{2}-1.31 \times \hat{\beta}_{3}}=1-\frac{21.4}{25.3}=0.15$. 
(Lipset 1960; Somer and McCoy 2018). On the first screen, treatment group subjects responded to the following prompt:

Democrats and Republicans are different types of people. For example, they are different in terms of social identities like race and culture, family, work, hobbies and interests, and where they live.

What about your identity makes you similar to [OWN PARTY]s? Please write a few sentences.

The second screen presented the following prompt:

Still thinking about identities - things like your culture, race, family, work, personality, hobbies, interests, or where you live-we also want to understand what makes people different.

What is something you share with other [OWN PARTY]s, but makes you different from [OTHER PARTY]s? Please write a few sentences.

Respondents were required to spend 20 seconds on each screen. In Study 1, independents who lean toward a party were included with that party; independents who did not prefer one party or the other were randomly assigned to a party. In Study 2, leaners were treated the same way, while "pure" independents were excluded from recruitment. Respondents in the control condition were prompted to name their favorite activity and describe what made them similar to people who enjoy it, then their least favorite activity and describe what made them different than people who enjoy it.

\section{Manipulation Check}

Following the treatment, respondents completed a five-item partisan social identity scale based on Huddy, Mason and Aaroe (2015) and Greene (1999). Figure 3 presents the results. In each row, the left panel displays the distribution of partisan identity and the right panel displays the average treatment effect. Study 1 successfully moved the partisan identity scale by by 0.105 standard deviations (Figure 3, second row; SE: 0.028; 95\% CI: $0.050,0.159) .{ }^{8}$ The top left panel of Figure 3 illustrates the small change to the distribution. The priming treatment moved partisan identity, but not radically so.

\footnotetext{
${ }^{8}$ Although I pre-registered one-sided tests for the purpose of assessing statistical significance, the confidence intervals listed in this section are all two-sided.
} 
Figure 3: Manipulation checks.
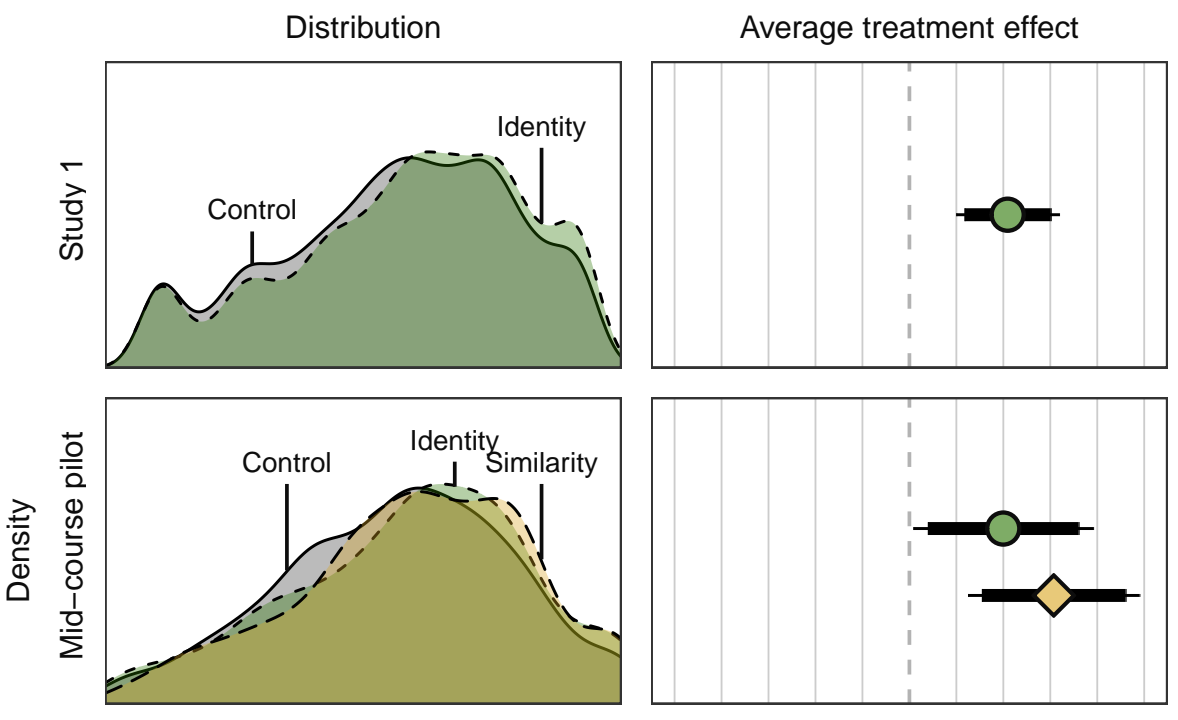

Treatment
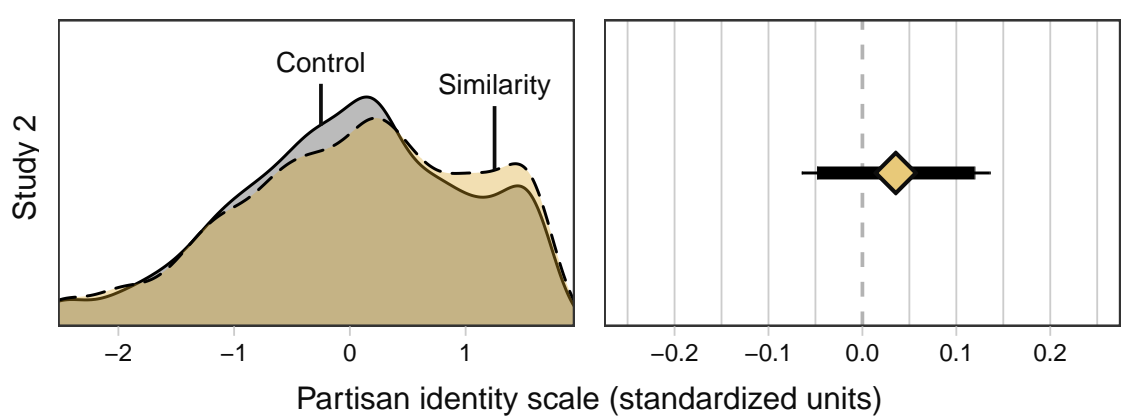

Note: For each study and treatment group, this figure plots the distribution of the partisan identity scale (left panel) and the average treatment effect on partisan identity (right panel). Thick and thin whiskers represent 90 and 95 percent confidence intervals (two-sided).

In Study 1, some respondents disputed the premise that partisanship was relates to social identities. ${ }^{9}$ This raised two concerns. Though there is no way to be sure, ${ }^{10}$ it seems likely that those who counter-argued would be less affected, or even negatively affected, by a treatment whose premise they disputed. Consequently, a mid-course pilot on Amazon Mechanical Turk (MTurk) assessed whether the treatment could be strengthened prior to fielding Study 2 (Figure 3, second row). The initial "Identity" treatment yielded a nearly identical point estimate to Study 1 (ATE: 0.100, SE: 0.049, CI: 0.004, 0.196). A version

\footnotetext{
${ }^{9}$ Despite this, there was no evidence of differential attrition. I used OLS to estimate the parameters in $M_{i}=\alpha+\beta Z_{i}+\epsilon_{i}$, where $M$ is an indicator for not finishing the candidate choices and $Z_{i}$ is the priming treatment. $\hat{\beta}=0.001$, s.e. $=0.004$.

${ }^{10}$ Because the control group was not exposed to the treatment, one cannot know which control respondents would have counter-argued.
} 
without explicit references to social identity, the "Similarity" treatment, yielded a larger point estimate (ATE: 0.154, SE: 0.047, CI: 0.062, 0.245). Though the estimates were not statistically distinguishable, the notions that the similarity treatment was (1) probably not weaker, (2) plausibly stronger, and (3) more credibly monotonic led to its use in Study 2.

Despite the successful pretest, Study 2's priming treatment did not have a statistically significant effect on partisan identity using either Lin's covariate-adjusted estimator (ATE: 0.035, SE: 0.051, CI: -0.065, 0.136) or a simple difference-in-means (ATE: -0.024, SE: 0.061, CI: $-0.144,0.095)$. The failed manipulation check limits Study 2's ability to speak to the downstream effect on support for electoral fairness.

\section{Effect on Support for Electoral Fairness}

Following the manipulation check, respondents completed the candidate choice tasks described above. Figure 4 presents separately estimated average treatment effects for the four types of scenarios. For Study 1, the treatment effect is plotted using two measures of support for candidate 1: the original, probabilistic scale and a binary transformation that records only the candidate preference.

The left panel displays the results for Study 1. The priming treatment increased support for neutral co-partisans facing opposite party opponents (center-left) and for antifairness co-partisans facing co-partisans opponents (center-right) by about 1 percentage point each. The effect for anti-fairness co-partisans facing opposite party co-partisans is about 2 percentage points, about what one would expect from adding the two estimates together. The right panel displays the estimate from Study 2. As one would expect given the failed manipulation check, Study 2 finds no effect.

The interpretation of Study 1's estimates for opposite-party matchups are clouded by the fact that separately from the electoral fairness positions, the priming treatment may boost support for copartisan candidates. To summarize the data in a manner that accounts 
Figure 4: Average treatment effect by type of candidate choice.

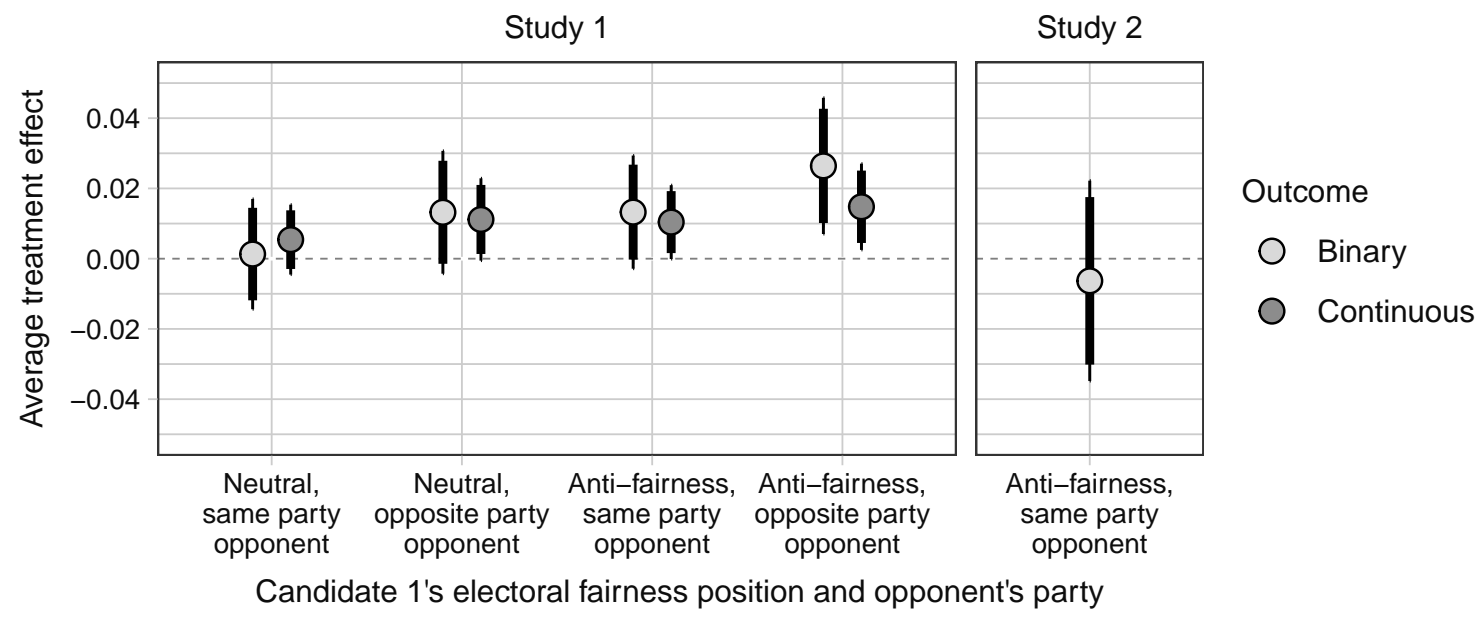

Note: Pooling across all electoral fairness positions, this figure displays the conditional average treatment effect of the writing task on support for candidates of different types. Light grey dots indicate that the outcome was a binary indicator of support for candidate 1; dark grey, the underlying six-point scale. Thick and thin whiskers represent 90 and 95 percent confidence intervals (two-sided).

for this, I use OLS to estimate the parameters in

$$
\begin{aligned}
Y_{i j}= & \alpha+\beta_{1} z_{i}+\beta_{2} z_{i} \times \mathrm{c} 1 \_ \text {neutral }_{i j}+\beta_{3} z_{i} \times \mathrm{c} 2 \text { opposite }_{i j}+ \\
& \beta_{4} \mathrm{c} 1 \_ \text {neutral }+\beta_{5} \mathrm{c} 2 \_ \text {opposite }_{i j}+\epsilon_{i j},
\end{aligned}
$$

where $i$ indexes respondents, $j$ indexes choices, $z_{i}$ is a treatment indicator, c1_neutral ${ }_{i j}$ indicates a matchup between democratically-netural candidates, and c2_opposite ${ }_{i j}$ indicates that the opponent was of the opposite party. This formulation is designed to maximize the precision on the estimate of $\beta_{1}$, the treatment effect on support for an anti-fairness candidate. A positive estimate of $\beta_{1}$ would indicate that the treatment boosted support for undemocratic candidates, net of its effect on support for co-partisan candidates. ${ }^{11}$ Study 2 was designed only to allow an estimate of $\beta_{1}$.

The estimates for Study 1 suggest that the partisan identity treatment reduced support

\footnotetext{
${ }^{11}$ The other terms have the following interpretations. $\beta_{2}$ : difference in treatment effects between antifairness and neutral candidates. $\beta_{3}$ : treatment effect on support for co-partisan candidates. $\beta_{4}$ : control group's difference in support for anti-fairness and neutral candidates. $\beta_{5}$ : control group difference in support between co-partisans with same- and opposite-party opponents. $\alpha$ : control group average level of support for an anti-fairness co-partisan.
} 
Table 3: Average treatment effect on support for electoral fairness.

\begin{tabular}{|c|c|c|c|c|c|c|c|}
\hline & & \multicolumn{4}{|c|}{ Study 1} & \multirow{2}{*}{\multicolumn{2}{|c|}{$\begin{array}{c}\text { Study } 2 \\
\text { Binary DV }\end{array}$}} \\
\hline & & \multicolumn{2}{|c|}{ Binary DV } & \multicolumn{2}{|c|}{ Continuous DV } & & \\
\hline \multicolumn{2}{|c|}{ Term } & Estimate & $p$ & Estimate & $p$ & Estimate & $p$ \\
\hline$\beta_{1}$ & Treatment & $\begin{array}{c}0.0136 \\
(0.0075)\end{array}$ & 0.04 & $\begin{array}{c}0.0101 \\
(0.0048)\end{array}$ & 0.02 & $\begin{array}{c}-0.0063 \\
(0.0145)\end{array}$ & 1.00 \\
\hline$\beta_{2}$ & Treatment $\times$ Neutral & $\begin{array}{l}-0.0126 \\
(0.0085)\end{array}$ & 0.07 & $\begin{array}{l}-0.0043 \\
(0.0054)\end{array}$ & 0.21 & & \\
\hline$\beta_{3}$ & Treatment $\times$ Opposite & $\begin{array}{c}0.0125 \\
(0.0091)\end{array}$ & 0.08 & $\begin{array}{c}0.0051 \\
(0.0061)\end{array}$ & 0.20 & & \\
\hline$\beta_{4}$ & Neutral & $\begin{array}{c}0.1780 \\
(0.0060)\end{array}$ & 0.00 & $\begin{array}{c}0.1107 \\
(0.0038)\end{array}$ & 0.00 & & \\
\hline$\beta_{5}$ & Opposite & $\begin{array}{c}0.1572 \\
(0.0063)\end{array}$ & 0.00 & $\begin{array}{c}0.1164 \\
(0.0043)\end{array}$ & 0.00 & & \\
\hline$\alpha$ & Constant & $\begin{array}{c}0.3174 \\
(0.0052)\end{array}$ & 0.00 & $\begin{array}{c}0.3847 \\
(0.0034)\end{array}$ & 0.00 & $\begin{array}{c}0.2683 \\
(0.0099)\end{array}$ & 0.00 \\
\hline
\end{tabular}

Note: Table presents estimates of the parameters in (4). Standard errors clustered by respondent. As onesided hypotheses were pre-registered, $p$-values are one-sided.

for electoral fairness. Table 3 displays estimates for each parameter in equation (4). Using the continuous scale suggests that among treated respondents, the average anti-fairness candidate gained 1.01 units of support on a 0-100 scale. The binary version suggests that on net, the treatment caused 1.36 percent more respondents to prefer the anti-fairness candidate. These results failed to replicate in Study 2. The estimate took the wrong sign and did not approach statistical significance.

In Study 1, opponents of anti-fairness candidates responded either by offering criticism or by proposing a reform to counter future actions like the one taken by their opponent (see Table 1). Figure 5 splits the estimates on this basis. When anti-fairness candidates faced a reformer, the anti-fairness candidate was preferred by about 3 percent more respondents when the reformer was a co-partisan and about 3.5 percenage points when the reformer was from the opposite party. Using the continuous measure, both effects were about 2 scale points. By contrast, anti-fairness candidates who face a co-partisan critic received no additional support. Anti-fairness candidates facing an opposite party critic received about 
Figure 5: Average treatment effect by style of opposition.
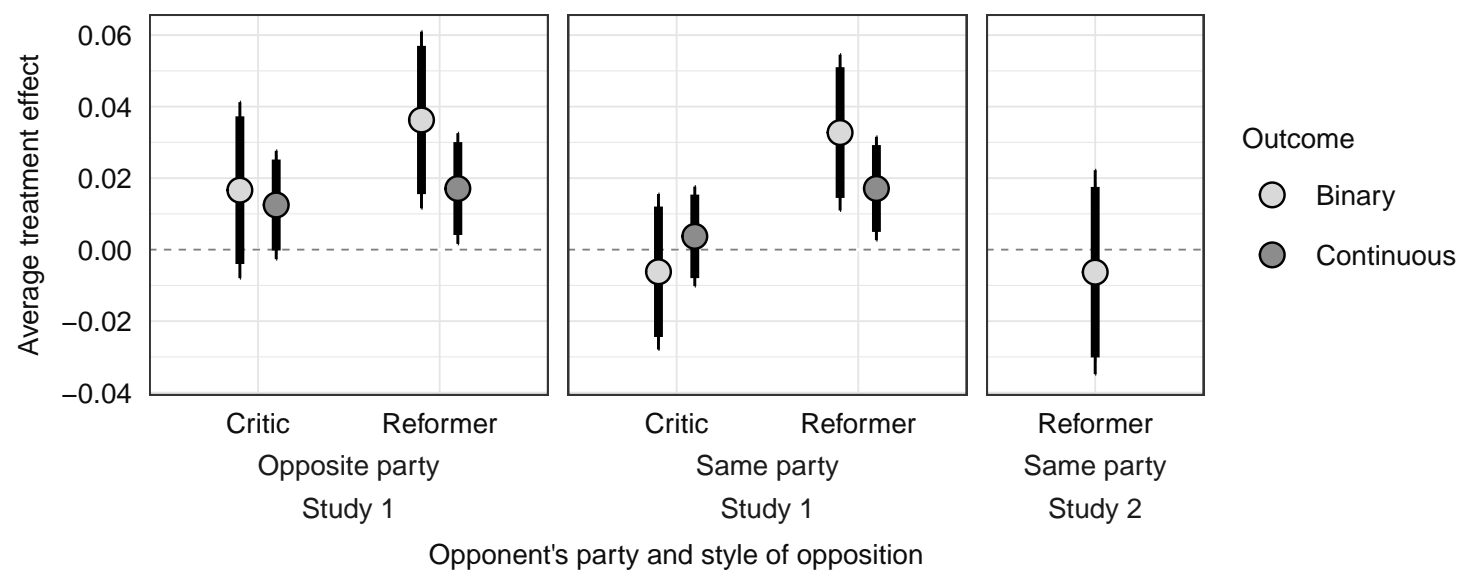

Note: Pooling across all violations of electoral fairness, this figure displays the conditional average treatment effect of the writing task on support for the anti-fairness candidate. In each panel, the left set of estimates are for anti-fairness candidates whose opponent responds by criticizing them, while the right set of estimates are for anti-fairness candidates whose opponent responds with a pro-fairness proposal. All other features identical to Figure 4.

1.5 percentage points and scale points of additional support, with neither estimate attaining statistical significance.

The appendix breaks these results down one step further, separately displaying treatment effect estimates according to the individual positions listed in Table 1 and the opponent's style of opposition. Within the four questions specifically related to manipulating vote totals - outright ballot fraud, closing polling stations in areas that support one's opponent, overseeing the administration of one's own election, and encouraging "party line changes" to voting rules - the treatment effects in Study 1 appear to increase as the infraction becomes less overt, suggesting that partisanship may have its largest effect on support for actions that subtly tilt the playing field. Naturally, this pattern fails to replicate in Study 2.

\section{Discussion}

The twin experimental approach provided weak, suggestive evidence that partisan identity may undermine support for electoral fairness. Examining treatment effect heterogeneity in a candidate choice experiment, respondents at the 90th percentile of partisan identity were 
about one-third less penalizing of anti-fairness candidates in cross-party candidate matchups than were respondents in the 10th percentile. In choices between copartisan candidates, those at the 90th percentile were roughly one-fifth less penalizing. To the author's knowledge, this is the first evidence of an inverse relationship between partisan identity and support for democratic values that has used a state-of-the-art measure of identity (Huddy et al. 2015; Greene 1999). In the initial study, experimental evidence seemed to back this finding. When respondents completing this task were exogenously primed to think of the overlap between their partisan and other social identities, an 0.1 standard deviation increase in partisan identity reduced the penalty for anti-fairness candidates by about 1 percentage point. However, in an attempted replication, statistically significant effects could not be detected on partisan identity or or support for electoral fairness.

The modest and inconsistently observed relationship between partisanship and support for electoral fairness could appear disconsonant in light of events subsequent to the data collection, in which many Americans expressed outright support for Donald Trump's effort to overturn the results of the 2020 presidential election. This juxtaposition highlights that in the real world, a complex constellation of factors appears to affect citizens' support for specific violations of democratic values, including opinion leadership on the part of media and public figures. Identity may play a role in citizen exposure to and acceptance of messages that encourage support for undemocratic actions. On its own, however, identity appears insufficient to make the prospect of partisan gain overwhelm pro-fairness sentiment. This is consistent with a contemporaneous research on affective polarization, which concludes that many of the apparent political effects of partisan affect "appear driven by omitted variable bias" (Broockman et al. 2021). Of course, one observer's omitted variable may be central to another observer's account of how affect or identity exerts its influence on politics. Given the difficulty of reproducing the real-world processes that lead to partisan identity or partisan affect, it is hard to say what it really means to consider these processes in isolation.

Given these less-than-conclusive results, why not conduct more studies? Though there 
is certainly a need for further research, three considerations informed the decision to close this line of inquiry. First, the design's resource-intensive nature. In both the case of treatment effect heterogeneity in the choice experiment and the priming treatment, the magnitude of the estimated relationships fell between 1 and 3 percentage points, which are small relative to what is statistically detectable in the typical survey experiment. Second, small effects are all the more problematic for efforts to examine how the effects of the priming treatment vary according to other factors, such as the particular electoral fairness violation or respondent characteristics. Proving that partisan identity causally reduces support for electoral fairness would be valuable, but an understanding of the contours of this relationship might be out of reach even with substantially larger samples. Third, concern that a search for a stronger priming treatment would lead the investigation to become atheoretic. Well-defined treatments are essential for an investigation of this nature. Unlike marketing or public health, wherein the name one assigns to the treatment is secondary to the goal of maximizing sales or wellbeing, treatments that are used to make inferences about the effect of partisan identity truly must work through that particular mechanism. Selecting treatments on the basis of their effect on measures of partisan identity, e.g. through the use of an algorithm (OfferWestort, Coppock and Green 2021), would risk selecting for unintentional violations of the suitable unit treatment value assumption (Gerber and Green 2012).

For better or for worse, these takeaways are less conclusive than one might like. The suggestive evidence and lessons for research design represent small steps, not the hoped-for giant leaps, toward understanding the relationship between partisan identity and support for democracy. 


\section{References}

Adler, David. 2018. "The Centrist Paradox: Political Correlates of the Democratic Disconnect.".

Ansolabehere, Stephen, Jonathan Rodden and James M. Snyder. 2008. "The strength of issues: Using multiple measures to gauge preference stability, ideological constraint, and issue voting." American Political Science Review 102(2):215-232.

Aronow, Peter M. and Benjamin T. Miller. 2019. Foundations of Agnostic Statistics. Cambridge University Press.

Bermeo, Nancy. 2016. "On Democratic Backsliding." Journal of Democracy 27(1):5-19.

Broockman, David E, Joshua L Kalla and Westwood. 2021. "Does Affective Polarization Undermine Democratic Norms or Accountability? Maybe Not." OSF Preprints (preprint).

Butler, Daniel M. and Jonathan Homola. 2017. "An Empirical Justification for the Use of Racially Distinctive Names to Signal Race in Experiments." Political Analysis 25:122-130.

Campbell, Angus, Phillip E. Converse, Warren E. Miller and Donald E. Stokes. 1960. The American Voter. Chicago: The University of Chicago Press.

Foa, Roberto Stefan and Yascha Mounk. 2016. "The Democratic Disconnect." The Journal of Democracy 27(3):5-17.

Fox, John. 2016. Applied Regression Analysis and Generalized Linear Models. 3 edited by Sage.

Gerber, Alan S. and Donald Green. 2012. Field Experiments. New York: W.W. Norton.

Gerber, Alan S., Gregory A. Huber and Ebonya Washington. 2010. "Party Affiliation, Partisanship, and Political Beliefs: A Field Experiment." American Political Science Review 104(4):720-744.

Graham, Matthew H and Milan W Svolik. 2020. "Democracy in America? Partisanship, Polarization, and the Robustness of Support for Democracy in the United States." The American Political Science Review 114(2):392-409.

Green, Donald P. and Bradley Palmquist. 1994. "How Stable is Party Identification?" Political Behavior 16(4):437-466.

Greene, Steven. 1999. "Understanding Party Identification: A Social Identity Approach.” Political Psychology 20(2):393-403.

Hainmueller, Jens, Jonathan Mummolo and Yiqing Xu. 2019. "How Much Should We Trust Estimates from Multiplicative Interaction Models? Simple Tools to Improve Empirical Practice." Political Analysis 27(2):163-92.

Hernandez, Enrique. 2016. Europeans' Views of Democracy. In How Europeans View and Evaluate Democracy, edited by Monica Ferrin and Hanspeter Kriesi. pp. 44-63.

Hoff, Peter D. 2009. A First Course in Bayesian Statistical Methods. Springer Texts in Statistics. 
Huddy, Leonie, Lilliana Mason and Lene Aaroe. 2015. "Expressive Partisanship: Campaign Involvement, Political Emotion, and Partisan Identity." American Political Science Review 109(1):1-17.

Hutchings, Vincent L. and Ashley E. Jardina. 2009. "Experiments on Racial Priming in Political Campaigns." Annual Review of Political Science 12:397-402.

Iyengar, Shanto, Mark D. Peters, Donald R. Kinder and Jon A. Krosnick. 1984. "The Evening News and Presidential Evaluations." Journal of Personality and Social Psychology 46:778-87.

Jackson, Melinda S. 2011. "Priming the Sleeping Giant: The Dynamics of Latino Political Identity and Vote Choice." Political Psychology 32(4):691-716.

Klar, Samara. 2013. "The Influence of Competing Identity Primes on Political Preferences." The Journal of Politics 75(4):1108-1124.

Krosnick, Jon A. and Donald R. Kinder. 1990. "Altering the Foundations of Support for the President Through Priming." American Political Science Review 84(2):497-512.

Levendusky, Matthew S. 2017. "Americans, Not Partisans: Can Priming American National Identity Reduce Affective Polarization?" The Journal of Politics 80(1):59-70.

Levitsky, Steven and Lucan A Way. 2010. Competitive Authoritarianism: Hybrid Regimes After the Cold War. New York: Cambridge University Press.

Lin, Winston. 2013. "Agnostic notes on regression adjustments to experimental data: Reexamining Freedman's critique." Annals of Applied Statistics 7(1):295-318.

Lipset, Seymour M. 1960. Political Man: The Social Bases of Politics. Garden City, NY: Doubleday.

Mason, Lilliana. 2018. Uncivil Agreement: How Politics Became Our Identity. Chicago: University of Chicago Press.

Offer-Westort, Molly, Alexander Coppock and Donald P. Green. 2021. "Adaptive Experimental Design: Prospects and Applications in Political Science." American Journal of Political Science (early view).

Schedler, Andreas. 2002. "Elections Without Democracy: The Menu of Manipulation." The Journal of Democracy 13(2):36-50.

Somer, Murat and Jennifer McCoy. 2018. "Deja vu? Polarization and Endangered Democracies in the 21st Century." American Behavioral Scientist 62(1):3-15.

Svolik, Milan. 2015. "Which Democracies Will Last? Coups, Incumbent Takeovers, and the Dynamic of Democratic Consolidation." British Journal of Political Science 45(4):715-738.

Svolik, Milan W. 2020. "When Polarization Trumps Civic Virtue: Partisan Conflict and the Subversion of Democracy by Incumbents." Quarterly Journal of Political Science 15(1):3-31.

Wooldridge, Jeffrey M. 2012. Introductory Econometrics: A Modern Approach. CENGAGE. 
Appendix to

\title{
Does Partisan Identity Reduce Support for Electoral Fairness?
}

\author{
Matthew H. Graham
}

March 23, 2021

\section{Contents}

A Supplemental Results $\quad \mathbf{2 2}$

A.1 Tables of Plotted Estimates . . . . . . . . . . . . . . . . . . 22

A.2 Results by Democracy Position . . . . . . . . . . . . . . . . . 24

A.3 Observational Evidence . . . . . . . . . . . . . . . . . . . 26

B Research Design $\quad \mathbf{2 8}$

B.1 Model of Anticipated Treatment Effects . . . . . . . . . . . . . . . . 28

B.2 Power Analysis for Study 2 . . . . . . . . . . . . . . . . . . . 30

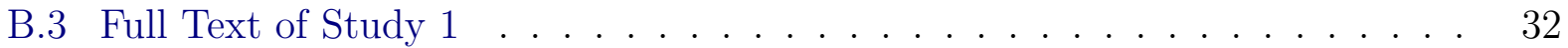

B.4 Candidate Choice Randomization for Study $1 \ldots \ldots 36$

B.5 Full Text of Study $2 \ldots \ldots \ldots$

B.6 Candidate Choice Randomization for Study $2 \ldots \ldots$. . . . . . . . 41

$\begin{array}{ll}\text { C Proofs } & 43\end{array}$

C.1 Fixed Baseline Assumption . . . . . . . . . . . . . . . . . . . . . . 43

C.2 Estimating Heterogeneous Effects with a Fixed Baseline . . . . . . . . . . . 44 


\section{A. Supplemental Results}

\section{A.1 Tables of Plotted Estimates}

Table A.4: Estimates plotted in Figure 3.

\begin{tabular}{lcccc}
\hline & & Mid-course & \multicolumn{2}{c}{ Study 2 } \\
\cline { 3 - 5 } & Study 1 & pilot & Bivariate & Lin \\
\hline Constant & -0.006 & -0.000 & 0.039 & -0.003 \\
& $(0.019)$ & $(0.033)$ & $(0.042)$ & $(0.034)$ \\
Identity treatment & $0.105^{* *}$ & $0.100^{*}$ & & \\
& $(0.028)$ & $(0.049)$ & & \\
Similarity treatment & & $0.154^{* *}$ & -0.025 & 0.036 \\
& & $(0.047)$ & $(0.061)$ & $(0.049)$ \\
\hline Adj. R ${ }^{2}$ & 0.003 & 0.003 & -0.000 & 0.359 \\
Num. obs. & 7166 & 2682 & 4005 & 3998 \\
\hline
\end{tabular}

Table A.5: Estimates plotted in Figure 4.

\begin{tabular}{|c|c|c|c|c|c|c|c|c|}
\hline Study & Type & $\begin{array}{l}\text { Opponent } \\
\text { party }\end{array}$ & Outcome & Term & Estimate & SE & $90 \% \mathrm{CI}$ & $95 \% \mathrm{CI}$ \\
\hline \multirow[t]{8}{*}{ Study 1} & Neutral & Same & Binary & $\begin{array}{l}\alpha \\
\beta\end{array}$ & $\begin{array}{l}0.497 \\
0.001\end{array}$ & $\begin{array}{l}0.005 \\
0.008\end{array}$ & $\begin{array}{c}(0.488,0.506) \\
(-0.012,0.014)\end{array}$ & $\begin{array}{c}(0.487,0.508) \\
(-0.014,0.017)\end{array}$ \\
\hline & & & Continuous & $\begin{array}{l}\alpha \\
\beta\end{array}$ & $\begin{array}{l}0.498 \\
0.005\end{array}$ & $\begin{array}{l}0.004 \\
0.005\end{array}$ & $\begin{array}{c}(0.493,0.504) \\
(-0.003,0.014)\end{array}$ & $\begin{array}{c}(0.491,0.505) \\
(-0.005,0.015)\end{array}$ \\
\hline & & Opposite & Binary & $\begin{array}{l}\alpha \\
\beta\end{array}$ & $\begin{array}{l}0.651 \\
0.013\end{array}$ & $\begin{array}{l}0.006 \\
0.009\end{array}$ & $\begin{array}{c}(0.640,0.661) \\
(-0.001,0.028)\end{array}$ & $\begin{array}{c}(0.638,0.663) \\
(-0.004,0.031)\end{array}$ \\
\hline & & & Continuous & $\begin{array}{l}\alpha \\
\beta\end{array}$ & $\begin{array}{l}0.609 \\
0.011\end{array}$ & $\begin{array}{l}0.004 \\
0.006\end{array}$ & $\begin{array}{l}(0.602,0.616) \\
(0.001,0.021)\end{array}$ & $\begin{array}{c}(0.601,0.617) \\
(-0.001,0.023)\end{array}$ \\
\hline & Anti-fairness & Same & Binary & $\begin{array}{l}\alpha \\
\beta\end{array}$ & $\begin{array}{l}0.316 \\
0.013\end{array}$ & $\begin{array}{l}0.006 \\
0.008\end{array}$ & $\begin{array}{c}(0.306,0.325) \\
(-0.000,0.027)\end{array}$ & $\begin{array}{c}(0.304,0.327) \\
(-0.003,0.029)\end{array}$ \\
\hline & & & Continuous & $\begin{array}{l}\alpha \\
\beta\end{array}$ & $\begin{array}{l}0.382 \\
0.010\end{array}$ & $\begin{array}{l}0.004 \\
0.005\end{array}$ & $\begin{array}{l}(0.376,0.388) \\
(0.002,0.019)\end{array}$ & $\begin{array}{c}(0.374,0.389) \\
(-0.000,0.021)\end{array}$ \\
\hline & & Opposite & Binary & $\begin{array}{l}\alpha \\
\beta\end{array}$ & $\begin{array}{l}0.476 \\
0.026\end{array}$ & $\begin{array}{l}0.007 \\
0.010\end{array}$ & $\begin{array}{l}(0.465,0.488) \\
(0.010,0.043)\end{array}$ & $\begin{array}{l}(0.463,0.490) \\
(0.007,0.046)\end{array}$ \\
\hline & & & Continuous & $\begin{array}{l}\alpha \\
\beta\end{array}$ & $\begin{array}{l}0.504 \\
0.015\end{array}$ & $\begin{array}{l}0.004 \\
0.006\end{array}$ & $\begin{array}{l}(0.497,0.511) \\
(0.004,0.025)\end{array}$ & $\begin{array}{l}(0.496,0.513) \\
(0.003,0.027)\end{array}$ \\
\hline Study 2 & & Same & Binary & $\begin{array}{l}\alpha \\
\beta\end{array}$ & $\begin{array}{c}0.268 \\
-0.006\end{array}$ & $\begin{array}{l}0.010 \\
0.014\end{array}$ & $\begin{array}{c}(0.252,0.285) \\
(-0.030,0.018)\end{array}$ & $\begin{array}{c}(0.249,0.288) \\
(-0.035,0.022)\end{array}$ \\
\hline
\end{tabular}


Table A.6: Estimates plotted in Figure 5.

\begin{tabular}{|c|c|c|c|c|c|c|c|c|c|}
\hline \multirow[b]{2}{*}{ Study } & \multirow[b]{2}{*}{ Type } & \multicolumn{2}{|c|}{ Opponent } & \multirow[b]{2}{*}{ Outcome } & \multirow[b]{2}{*}{ Term } & \multirow[b]{2}{*}{ Estimate } & \multirow[b]{2}{*}{$\mathrm{SE}$} & \multirow[b]{2}{*}{$90 \% \mathrm{CI}$} & \multirow[b]{2}{*}{$95 \%$ CI } \\
\hline & & Party & Style & & & & & & \\
\hline \multirow[t]{15}{*}{ Study 1} & Anti-fairness & Same & Reformer & Binary & $\alpha$ & 0.294 & 0.008 & $(0.281,0.306)$ & $(0.279,0.309)$ \\
\hline & & & & & $\beta$ & 0.033 & 0.011 & $(0.014,0.051)$ & $(0.011,0.055)$ \\
\hline & & & Critic & & $\begin{array}{l}\alpha \\
\beta\end{array}$ & $\begin{array}{c}0.337 \\
-0.006\end{array}$ & $\begin{array}{l}0.008 \\
0.011\end{array}$ & $\begin{array}{l}(0.325,0.350) \\
(-0.0240 .012)\end{array}$ & $\begin{array}{c}(0.322,0.352) \\
(-0.028,0.016)\end{array}$ \\
\hline & & & Reformer & Continuous & $\alpha$ & 0.371 & 0.005 & $(0.363,0.379)$ & $(0.361 \quad 0.381)$ \\
\hline & & & & & $\beta$ & 0.017 & 0.007 & $(0.005,0.029)$ & $(0.003,0.032)$ \\
\hline & & & Critic & & $\alpha$ & 0.392 & 0.005 & $(0.384,0.400)$ & $(0.383,0.402)$ \\
\hline & & & & & $\beta$ & 0.004 & 0.007 & $(-0.008,0.015)$ & $(-0.010,0.018)$ \\
\hline & & Opposite & Reformer & Binary & $\alpha$ & 0.464 & 0.009 & $(0.450,0.479)$ & $(0.447,0.482)$ \\
\hline & & & & & $\beta$ & 0.036 & 0.013 & $(0.016,0.057)$ & $(0.012,0.061)$ \\
\hline & & & Critic & & $\alpha$ & 0.488 & 0.009 & $(0.474,0.503)$ & $(0.471,0.506)$ \\
\hline & & & & & $\beta$ & 0.017 & 0.013 & $(-0.004,0.037)$ & $(-0.008,0.041)$ \\
\hline & & & Reformer & Continuous & $\alpha$ & 0.501 & 0.005 & $(0.492,0.510)$ & $(0.490,0.512)$ \\
\hline & & & & & $\beta$ & 0.017 & 0.008 & $(0.004,0.030)$ & $(0.002,0.033)$ \\
\hline & & & Critic & & $\alpha$ & 0.507 & 0.005 & $(0.498,0.516)$ & $(0.497,0.518)$ \\
\hline & & & & & $\beta$ & 0.012 & 0.008 & $(-0.000,0.025)$ & $(-0.003,0.028)$ \\
\hline \multirow[t]{2}{*}{ Study 2} & & Same & Reformer & Binary & $\alpha$ & 0.268 & 0.010 & $(0.252,0.285)$ & $(0.249,0.288)$ \\
\hline & & & & & $\beta$ & -0.006 & 0.014 & $(-0.030,0.018)$ & $(-0.035,0.022)$ \\
\hline
\end{tabular}




\section{A.2 Results by Democracy Position}

Prior to obtaining the results of study 2, a previous version of this manuscript included an exploratory analysis of how study 1's treatment effects varied according to the six distinct

violations of electoral fairness. For transparency and completeness, this section presents a version of that analysis.

\section{Unpacking the Treatment Effects}

What explains the overall average treatment effects presented above? For a closer look at what may explain treated respondents' greater preferences for anti-fairness candidates, this section examines treatment effects disaggregated according to the six anti-fairness positions (Figure A.6). As was the case in the overall effects above, Figure A.6 suggests that the partisan identity treatment had the strongest effect in choices that pitted an anti-fairness candidates against reformers.

Four of the electoral fairness positions dealt with efforts to manipulate vote totals (see Table 1 for full wording). These positions were designed to vary in the overtness of the violation. The first action, employing a campaign staff member who collected absentee ballots and filled them in, is the largest-scale outright fraud perpetrated in American elections in recent memory. The second, hiring a consultant to go around the state recommending polling place closures in places that support your opponent - as did then-Georgia Secretary of State Brian Kemp during his successful gubernatorial campaign in the 2018 election - constitutes a fairly clear violation of electoral fairness. The third, overseeing one's own election rather than resigning as Secretary of State - also an action (not) taken by Kemp in 2018 - takes advanage of an institutional feature that is well-designed to enable violations of electoral fairness, but is not clearly a violation unless interpreted in the context of what else Kemp did in this role. The fourth, encouraging local officials to make "party line changes" to voting rules, is an action taken by the executive director of the North Carolina Republican Party, Dallas Woodhouse. Woodhouse's instructions are a mere allusion to rigging the game that could be supported by a majoritarian conception of democracy. If your party won the election, why not make changes along party lines?

Comparing the treatment effects on support for these types of anti-fairness candidates suggests that partisan identity undermines support for electoral fairness the most when the implications of the anti-fairness action are ambiguous. In Figure A.6, the partisan identity treatment had no effect on support for candidates who committed the "closed polling stations" or "absentee ballot fraud" actions. By contrast, candidates described as having taken the "party line changes" action - which, to boost comparability, was met with the same reform proposal as the "close polling places" action - saw a 5 scale point boost in support, which translated into a 10 percentage point increase in preference for the anti-fairness candidate. Relative to the anti-fairness candidate's level of support in the control group, this suggests that on net, the treatment caused about one-sixth of respondents to shift from favoring a reform candidate who favors non-partisan administration of elections to an antifairness candidate who wants to use partisan control of elections to cement his or her party's 
Figure A.6: Average treatment effect by electoral fairness position and opponent characteristics.

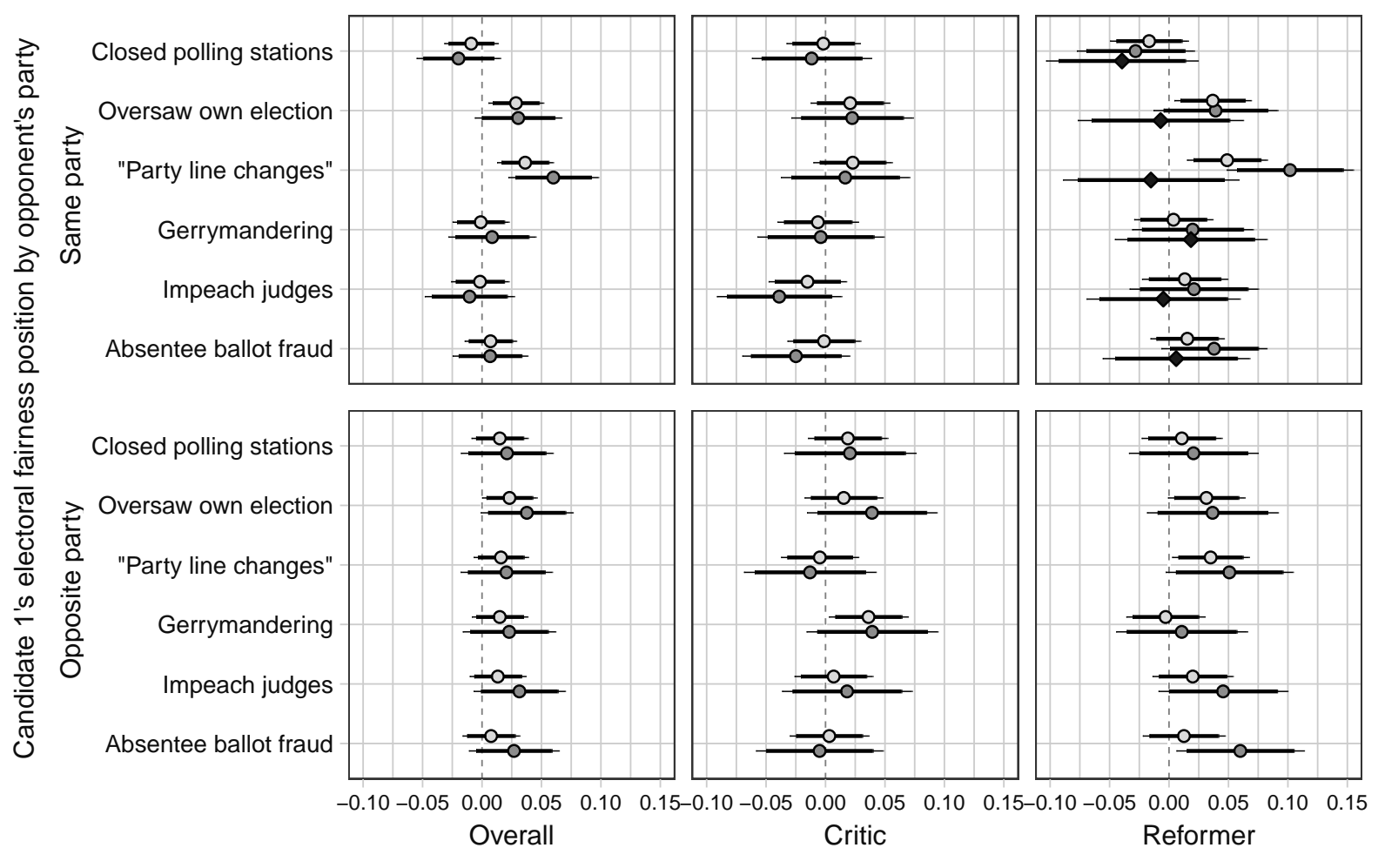

Estimate by opponent's electoral fairness position

$\circ$ Study 1 (continuous) ○ Study 1 (binary) $\diamond$ Study 2 (binary)

Note: Separately for each violation of electoral fairness, opponent response, and opponent partisanship, this figure displays the average treatment effect of the writing task on candidate support. The top row displays estimates for anti-fairness candidates facing co-partisan opponents; the bottom row, anti-fairness candidates facing opposite party opponents. The left column presents pooled estimates for both types of opponent responses, while the right panel separates them. Electoral fairness positions are displayed in the same order as in Table 1. The caption to Figure 4 interprets the whiskers, shapes, and colors. 
hold on power. The "oversaw own election" action falls between party line changes and the two relatively overt actions.

The remaining two violations dealt with redistricting, which skews elections by redistributing votes rather than suppressing or manipulating them. The point estimates tend to be positive but smaller, and are only occasionally distinguishable from zero. While these positions appear to have contributed something to the overall effect of the partisan identity treatment on support for electoral fairness, there is not enough evidence of differences between them to speculate as to what may have driven the pattern of effects.

\section{A.3 Observational Evidence}

Despite strong theoretical reasons to expect a negative relationship between partisan identity and support for democracy, this phenomenon has proven challenging to observe at the individual level. In fact, traditional methods of measuring the relationship between support for democracy and other factors suggest the opposite of this expectation. For each level of the standard seven-point party identification scale, Figure A.7 displays the distribution of what is perhaps the most-analyzed survey question on support for democracy, "How important is it for you to live in a country that is governed democratically?" Researchers slice this question in all manner of ways, but no matter how you slice it - the mean response (e.g., Hernandez 2016), the percentage of respondents saying 10 out of 10 (e.g., Foa and Mounk 2016), the median response, or most other cutoffs - strong partisans state at least as high a level of support for democracy as do other Americans. Similar patterns appear using other common measures of stated support for democracy, as well as using a liberal-conservative ideological scale rather than partisan identification (Adler 2018).

As a tool for learning about how stronger partisan attachments affect support for democracy, these measures have three key shortcomings. First, there is no tradeoff between one's own partisan identity and supporting democracy. In elections, defending democracy generally requires more than disapproving of a general practice - it requires partisans against a candidate who engaged in that practice for the express purpose of helping the partisan team. Second, there is no exogenous variation in partisan identity. It is impossible to be sure that the observed associations are due to partisan identity itself or some other factor. Third, although the question wording used to measure the standard seven-point party identification scale is plainly identity-focused in its language, it is also likely to have more measurement error than the multi-item scale used in the main text. 
Figure A.7: Stated importance of living in a democracy by partisan identity.

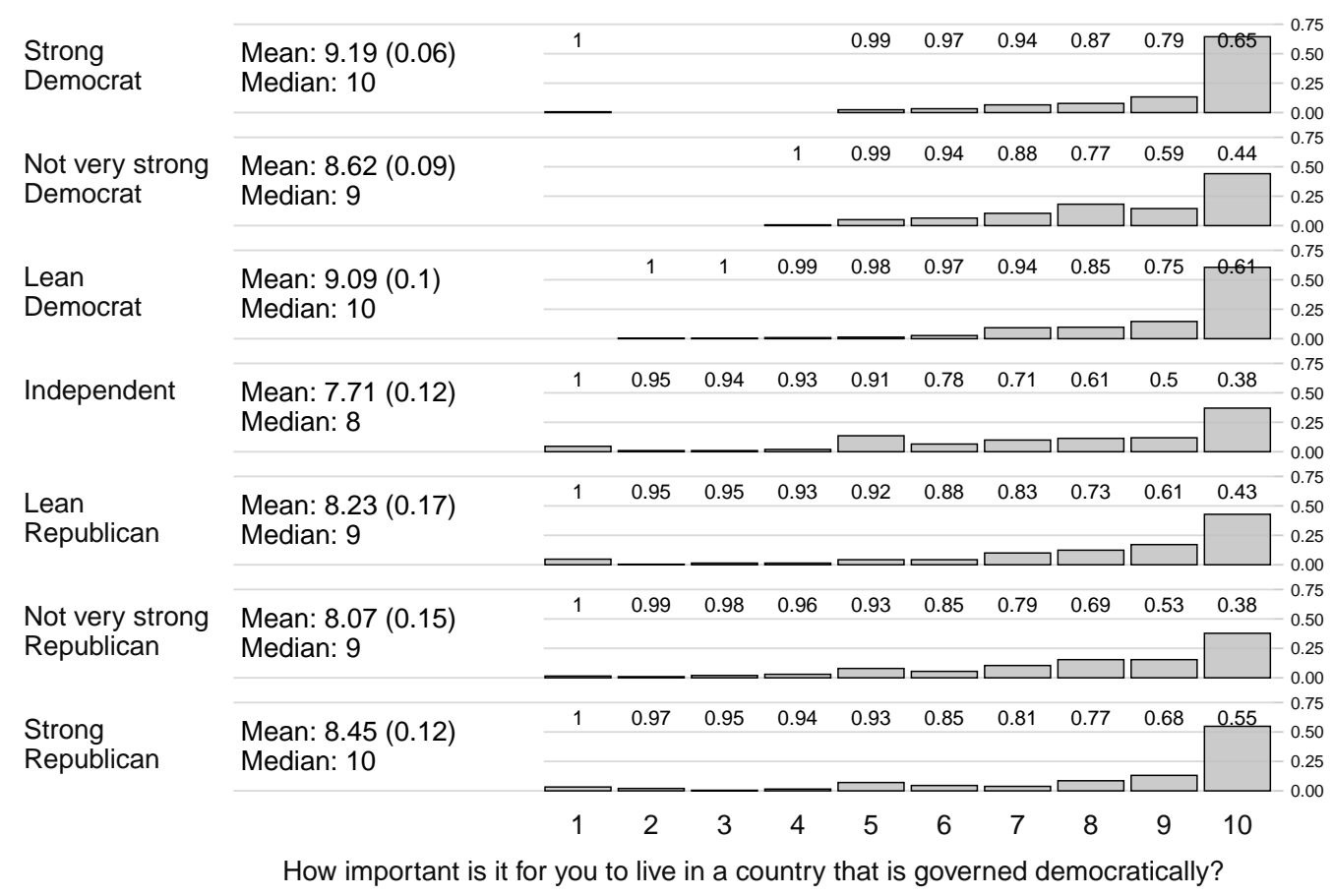

Note: For each level of the seven-point party identification scale, this figure displays the response distribution and several summary statistics for the question, "How important is it for you to live in a country that is governed democratically?". The mean, standard error of the mean, and median appear next to the name of each partisan group. To the right, the bars plot the probability mass function. The numbers above the bars are the cumulative percentage of respondents who stated at least that level. For example, in the top right, the 0.87 means " 87 percent of strong Democrats chose 8, 9, or 10." Source: Bright Line Watch, October 2019 public survey. Downloaded December 5, 2019. 


\section{B. Research Design}

\section{B.1 Model of Anticipated Treatment Effects}

The priming experiment aims to a random subset of respondents to think like stronger partisans, then measuring the downstream effect on support for electoral fairness in candidate choice scenarios. To ground expectations for this strategy, this section presents a simple formalization of the strategy for detecting this downstream effect. This formalization informed the design of Study 1 and the decisions about how to deal with the tradeoff between survey length and sample size presented by Study 2. With the exception of the opening and final paragraphs, this section is identical to a draft manuscript that was completed before Study 2's results were known.

Consider a variable that measures subject $i$ 's strength of partisanship, $P_{i, z}$. Subject $i$ is delivered a priming treatment that encourages $i$ to move $P_{i, z}$ toward $P_{i, T} \geq P_{i, z}$. Let the respondent's treated outcome be a precision-weighted sum of their baseline, $P_{i, z=0}$, and the level encouraged by treatment.

$$
P_{i, 1}=P_{i, 0} \frac{\rho_{0}}{\rho_{0}+\rho_{T}}+P_{i, T} \frac{\rho_{T}}{\rho_{0}+\rho_{T}}
$$

where $\rho_{0}$ and $\rho_{T}$ are the precision (i.e., inverse variance) of $P_{i, 0}$ and $P_{i, T}$. Consequently, the treatment effect of $T, \tau_{i}^{P}$, is

$$
\begin{aligned}
P_{i, 1}-P_{i, 0} \equiv \tau_{i}^{P} & =P_{i, 0} \frac{\rho_{0}}{\rho_{0}+\rho_{T}}+P_{i, T} \frac{\rho_{T}}{\rho_{0}+\rho_{T}}-P_{i, 0} \\
& =\left(P_{i, T}-P_{i, 0}\right) \frac{\rho_{T}}{\rho_{0}+\rho_{T}}
\end{aligned}
$$

Two straightforward implications of this expression are that the average treatment effect is (1) decreasing in the precision (i.e., increasing in the uncertainty or variance) of the respondent's baseline attitude and (2) increasing in the difference between the baseline level of the attitude and the level encouraged by treatment $\left(P_{i, T}-P_{i, 0}\right)$.

Now consider a choice between two candidates, $C 1$ and $C 2$. Let $Y_{i}$ be an indicator that equals 1 if $C 1$ is chosen and 0 otherwise. For simplicity, assume that the probability of choosing $C 1$ is an additive linear function of four factors: the level of the respondent's partisanship, $P_{i, z}$; the candidates' partisanship, $P_{C 1}$ and $P_{C 2}$; the candidates' democracy positions, $D_{C 1}$ and $D_{C 2}$; and an error term $\epsilon_{i}$ that captures all of the other things that influence candidate choice. The probability of choosing candidate 1 is

$$
\begin{aligned}
\operatorname{Pr}\left(Y_{i, z}=1\right) & =\alpha+\beta_{1} P_{i, z}\left(D_{C 1}-D_{C 2}\right)+\beta_{2}\left(D_{C 1}-D_{C 2}\right)+\beta_{3} P_{i, z}\left(P_{C 1}-P_{C 2}\right)+\epsilon_{i} \\
& =\alpha+\beta_{1} P_{i, z} \Delta_{D}+\beta_{2} \Delta_{D}+\beta_{3} P_{i, z} \Delta_{P}+\epsilon_{i}
\end{aligned}
$$

where $\Delta_{D} \equiv\left(D_{C 1}-D_{C 2}\right)$ and $\Delta_{P} \equiv\left(P_{C 1}-P_{C 2}\right)$. 
In the experiment, the quantity of interest is the average difference in choice probabilities between states of the world $z=1$ and $z=0$. For any particular respondent $i$, this difference is $\operatorname{Pr}\left(Y_{i, 1}=1\right)-\operatorname{Pr}\left(Y_{i, 0}=1\right) \equiv \tau_{i}$.

$$
\begin{aligned}
\tau_{i} & =\alpha_{1}-\alpha_{0}+\beta_{1} P_{i, 1} \Delta_{D}-\beta_{1} P_{i, 0} \Delta_{D}+\beta_{2} \Delta_{D}-\beta_{2} \Delta_{D}+\beta_{3} P_{i, 1} \Delta_{P}-\beta_{3} P_{i, 0} \Delta_{P}+\epsilon_{i} \\
& =\beta_{1} \tau_{i}^{P} \Delta_{D}+\beta_{3} \tau_{i}^{P} \Delta_{P}+\epsilon_{i}
\end{aligned}
$$

where, as above, $\tau_{i}^{P}$ is the treatment effect on partisanship. The average downstream treatment effect on support for democracy from this design is $\frac{1}{N} \sum_{i}^{N} \tau_{i}$.

From expressions (5) and (6), a few key implications emerge.

1. The ATE is decreasing in the precision of the baseline attitude. This implies that for an attitude like partisan identity, which is precise at baseline, we should expect small downstream effects. Given the realities of statistics, this leaves the design in danger of failing to detect the downstream effect.

2. The ATE is increasing in the difference between the level of the baseline attitude and the level of the attitude encouraged by treatment. This implies that one way to boost the detectability of the downstream effects is to increase the strength of the partisan identity treatment.

3. The ATE is increasing in the difference between the candidates' democracy positions. This implies that another way to boost the detectability of the downstream effects is to increase the difference between the candidates' democracy positions.

4. When $\Delta_{P} \neq 0$, the ATE combines the downstream effect of partisan identity on support for democracy, $\beta_{1}$, and the downstream effect of partisan identity on support for copartisan candidates, $\beta_{3}$. When $\Delta_{P}=0$, the ATE reflects only the downstream effect of partisan identity on preferences for the candidates' democracy positions. This implies that in order to isolate the effect of treatment on support for democracy, it will be necessary either to include some candidate choices in which $\Delta_{P}=0$ (directly isolating $\beta_{1}$ ) or some candidate choices in which $\Delta_{D}=0$ (allowing an estimate of $\beta_{3}$, which in turn enables one to back out $\beta_{1}$ ).

These implications are reflected in the design of both studies. Study 1 used a large sample (\#1), always pitted anti-fairness candidates against pro-fairness candidates rather than neutral candidates (\#3), and included choices pitting two neutral candidates to estimate the treatment's baseline effect on support for copartisans facing opposite-party opponents (\#4). For Study 2, the tradeoff between survey length and sample size was determined using an explicit power calculation (\#1; see Section B.2). A mid-course pilot to examine a potential weakness in the treatment (\#2). In light of the smaller-than-anticipated treatment effect in Study 1, the largest contrast in electoral fairness positions was favored in Study 2 (\#3). Given the impracticality of including enough choice types to account for the baseline effect of treatment on partisan identity, only same-party choices were considered (\#4; see Section B.2). 


\section{B.2 Power Analysis for Study 2}

This section presents the power analysis for Study 2 exactly as it appeared in the proposal for funding. I begin by describing the process by which I decided to focus on undemocratic candidates with same-party opponents. I then describe the simulation procedure I used to determine the optimal tradeoff between the number of respondents, survey units, and choice tasks. Finally, I present the results.

\section{Selection of Matchup Types}

To test the viability of the proposed research design, I conducted an initial study on Lucid $(N=6500)$. Subjects were randomly assigned with equal probability to the partisan identity treatment or an active control. All subjects then completed twelve total candidate choice tasks in the categories described in the proposal. For each subject, the twelve choices were split evenly between the following four categories:

1. Two of the respondent's co-partisans, both democratically neutral.

2. Two of the respondent's co-partisans, one undemocratic.

3. A co-partisan versus an other-party candidate, both democratically neutral.

4. A co-partisan versus an other-party candidate, with the co-partisan undemocratic.

In the first stage of the power analysis, I assessed how much of this design I could afford to replicate through TESS. I began by estimating the difference in treatment effects between pairs of matchup types, ${ }^{12}$ using randomly chosen subsets of the data that match TESS's limits on the number of subjects and survey units. Unfortunately, because interaction effects can rarely be as precisely estimated as main effects, my power to detect a statistical difference between matchup types was almost always less than 50 percent, even when I assumed 2 percentage point treatment effects. Consequently, instead of trying to estimate how the treatment works differently in different situations, I decided to propose a study that attempts to replicate the effects found in just one of the initial study's four matchup types. I chose the second matchup type, an undemocratic co-partisan against another co-partisan, because holding party constant means that the only systematic difference between the two candidates is their support for democracy.

\section{Estimated Effect Sizes}

I conducted the power analysis using two different anticipated effect sizes. The first effect size, 1.3 percentage points, is the point estimate presented in Figure ??. The second effect size, 2 percentage points, assumes that at least one of my design modifications - namely, the focus on matchups with pro-democratic candidates, the stronger treatment, and the switch to a higher-quality sample - boosts the average treatment effect. If the initial study's results are a good guide, focusing on matchups with pro-democratic candidates is sufficient on its

\footnotetext{
${ }^{12}$ In other words, I tried to statistically detect differences between the treatment effects in Figure 4.
} 
own to drive the effects over 2.0 percentage points, but I wish to be conservative in my assumptions about the cumulative effect of design tweaks.

\section{Simulation Procedure}

I used the data from matchup type 2 to simulate the design's statistical power. I tested versions of the design featuring two, three, four, and five choice tasks, each time adjusting the sample size to match the expected number of survey units. Because the treatment and manipulation check occupy four survey units, the two-matchup version assumed 8,000 respondents; the three-matchup version, 6,200; the four-matchup version, 5,600; and the five-matchup version, 5,000.

To construct datasets that differed in the number of choice tasks but were otherwise comparable, I took two steps. First, depending on the number of choice tasks, I randomly dropped or duplicated choice tasks so that each respondent has the correct number. Second, to guarantee that idiosyncracies in this randomization would not distort the comparisons, I ensured that each version of the dataset (2-5 choice tasks) had exactly the same treatment effect. To accomplish this, I compared each dataset's difference in means to the desired treatment effect, calculated the number of choice tasks that need to be changed to get the exact effect desired, and randomly selected exactly that number of choices to be changed.

To calculate statistical power I conducted 1,000 simulations using the same procedure for each dataset. In each simulation, I began by resampling the desired number of respondents with replacement. I then used OLS to estimate the average treatment effect on support for undemocratic candidates, always clustering standard errors at the respondent level. Finally, I stored the average treatment effect estimate, standard error, and p-value.

\section{Results}

The design is well-powered to detect 2 percentage point effects and moderately powered to detect 1.3 percentage point effects. For each version of the design and assumed effect size, Table B.7 presents the percentage of simulations in which the null hypothesis of no average treatment effect could be rejected at the $\alpha<0.05$ level using a one-sided test. Regardless of the assumed true effect size, power peaks in the three-task design with 6,200 respondents. If the true effect size is 2 percentage points, this design has about a 90 percent chance of detecting it.

Though this level of statistical power is sufficient to make the proposed design worth fielding, the fact that it takes such a large number of respondents to reach this level of power reinforces my decision to propose focusing on one of the four matchup types used in the initial study. Survey experiments usually attempt to manipulate aspects of peoples' belief systems that are much more malleable than party identification. In my view, the importance of partisanship's

effect on support for democracy justifies using a resource-intensive design to measure small effects. 
Table B.7: Statistical Power by Number of Tasks and Assumed True Effect Size

\begin{tabular}{cccc}
\hline & & \multicolumn{2}{c}{ Effect Size } \\
Tasks & $\mathrm{N}$ & 1.3 p.p. & 2.0 p.p. \\
\hline 2 & 8000 & 0.57 & 0.88 \\
3 & 6200 & 0.66 & 0.90 \\
4 & 5600 & 0.58 & 0.86 \\
5 & 5000 & 0.49 & 0.82 \\
\hline
\end{tabular}

\section{B.3 Full Text of Study 1}

This section presents the full text of Study 1.

\section{7-point Party ID Scale}

Generally speaking, do you think of yourself as a Democrat, a Republican, or an independent?

[Democrat, Republican, Independent, Other]

[Display if Democrat or Republican is selected:] Would you say you are a strong [PARTY]?

[Strong [PARTY], Not a strong [PARTY]]

[Display if Democrat is not selected AND Republican is not selected:] Do you think of yourself as closer to the Republican party or the Democratic party?

[Closer to Democrat, Closer to Republican, Neither]

\section{Attention Check}

Note: the analysis in the main text does not condition on this variable.

We would like to know a little more about you. Specifically, we want to know if you read directions. For this question, please choose both pink and green even if you prefer some other color.

What is your favorite color?

[Blue, Brown, Green, Orange, Pink, Purple, Red, Yellow, None of the above] 


\section{Treatment}

Displayed if $z=1$. Simple random assignment, $p=0.5$.

Democrats and Republicans are different types of people. For example, they are different in terms of social identities like race and culture, family, work, hobbies and interests, and where they live.

What about your identity makes you similar to [OWN PARTY]s? Please write a few sentences.

[text box]

The "next" button will appear in 20 seconds.

\section{PAGE BREAK}

Still thinking about identities - things like your culture, race, family, work, personality, hobbies, interests, or where you live - we also want to understand what makes people different.

What is something you share with other [OWN PARTY]s, but makes you different from [OTHER PARTY]s? Please write a few sentences.

$[$ text box $]$

The "next" button will appear in 20 seconds.

\section{Active Control}

Displayed if $z=0$. Simple random assignment, $p=0.5$.

What is your favorite activity? [in-line text box]

What makes you different from people who enjoy this activity? Please write a few sentences. [text box]

The "next" button will appear in 20 seconds.

\section{PAGE BREAK}

What is your favorite activity? [in-line text box]

What makes you different from people who enjoy this activity? Please write a few sentences. [text box] 
The "next" button will appear in 20 seconds.

\section{Party Identity Scale}

For the following questions, please fill in "Democrat" if the respondent is a Democrat or leans toward the Democrats. Please fill in "Republican" if the respondent is a Republican or leans towards the Republicans.

Do you agree or disagree with the following statements?

When I talk about [party]s, I say "we" rather than "they."

[Strongly disagree, Disagree, Slightly disagree, Slightly agree, Agree, Strongly agree]

I have many qualities that are typical of [party]s.

[Strongly disagree, Disagree, Slightly disagree, Slightly agree, Agree, Strongly agree]

When someone praises [party]s, it feels like a personal compliment.

[Strongly disagree, Disagree, Slightly disagree, Slightly agree, Agree, Strongly agree]

I think of myself as a [party].

[Strongly disagree, Disagree, Slightly disagree, Slightly agree, Agree, Strongly agree]

Being a [party] is important to me.

[Strongly disagree, Disagree, Slightly disagree, Slightly agree, Agree, Strongly agree]

\section{Candidate Choice Instructions}

Your next task is to choose between pairs of candidates for Congress. There will be three total choices. On each page, the "next" button will appear after 20 seconds.

\section{Candidate Choices}

[Each respondent completed twelve candidate choice tasks. In the main text, a screen shot appears in Figure 1.]

\section{Debrief}

We would like to know how you made your last choice. 
[Final candidate choice is displayed again.]

Why did you prefer [name of chosen candidate]? Please write a sentence or two.

[text box]

\section{PAGE BREAK}

We have one more question about the same two candidates.

[Final candidate choice is displayed again.]

Which candidate is more likely to respect norms of democratic political competition?

[Last names of both candidates] 


\section{B.4 Candidate Choice Randomization for Study 1}

This section describes the candidate choice randomization scheme.

Political party: Each candidate has the same political party as the respondent.

Name, race/ethicity, and gender: The following 24 names were randomly assigned to candidates using the Fisher-Yates shuffle. Each candidate's race/ethnicity and gender was displayed along with their name. The names and their association with other characteristics were randomly selected from the list appearing in Butler and Homola (2017).

Table B.8: Candidate names.

\begin{tabular}{|c|c|c|c|}
\hline Black & Hispanic & \multicolumn{2}{|c|}{ White } \\
\hline \multicolumn{4}{|c|}{ Women } \\
\hline Ebony Mosley & Blanca Ramirez & Allison Nelson & Kathryn Evans \\
\hline Jasmin Jefferson & Catalina Hernandez & Hannah Phillips & Molly Kruger \\
\hline Latonya Rivers & Rosa Perez & Katherine Adams & Sarah Miller \\
\hline \multicolumn{4}{|c|}{ Men } \\
\hline Jamal Gaines & Carlos Torres & Dylan Schwartz & Jake Clark \\
\hline LaShawn Banks & Eduardo Lopez & Garrett Novak & Scott King \\
\hline Terrance Booker & Jose Sanchez & Geoffrey Martin & Tanner Smith \\
\hline
\end{tabular}

Age: Random integers between 35 and 65, drawn with equal probability.

Biographical traits: In each choice between neutral candidates, two of the following professions were drawn without replacement and with equal probability:

- Founded and ran a successful small business in [her/his] hometown.

- Worked as a corporate lawyer for a large firm specializing in patents.

- As a federal prosecutor, oversaw hundreds of criminal convictions.

- Served in Afghanistan as a military intelligence officer.

- Served in Iraq, where [s/he] lost [her/his] leg to a roadside bomb.

- Served in the state legislature and became [her/his] party's leader.

- Self-funded [her/his] campaign with money [s/he] earned as a corporate executive.

- Worked for a large bank rose to become Chief Financial Officer.

- Served two terms as the mayor of [her/his] hometown.

- Served one term as the governor of [her/his] home state.

- Former TV and radio host making [her/his] first run for political office.

- Former teacher who first ran for office at [her/his] students' encouragement.

- Founded a technology company, then sold it for millions and entered politics. 
- Former speechwriter and staffer for a member of Congress in Washington.

- As a high school athlete, led [her/his] basketball team to the state championship.

- Former track star who won a bronze medal at the summer Olympics.

Policy positions: In each choice, two of the following were drawn with equal probability:

- Supports simplifying the tax code so that everyone pays their fair share.

- Supports replacing individual income taxes with a value-added tax.

- Supports putting a stop to rising prescription drug prices.

- Supports making health care more affordable for all Americans.

- Supports allowing Americans to buy cheaper prescription drugs from Canada.

- Supports laws to prevent companies from collecting personal data without permission.

- Supports aggressive anti-trust enforcement against Amazon, Facebook, and Google.

- Supports letting illegal immigrants earn citizenship if tough enforcement measures come first.

- Supports increasing spending on infrastructure projects, including roads and bridges.

- Supports a constitutional amendment requiring Congress to balance the budget every year.

- Supports a constitutional amendment limiting members of Congress to two terms.

- Supports paying teachers more when their students do well on standardized tests.

Democracy positions: Using the Fisher-Yates shuffle, each row of Table 1 in the main text was assigned to one candidate choice. Using an independent Fisher-Yates shuffle, exactly three anti-fairness candidates were designated to face a critic and three to face a reformer. 


\section{B.5 Full Text of Study 2}

This section presents the full text of Study 2 as it appeared in the proposal for funding and the initial instructions to programmers. Note that partisanship was measured prior to the survey based on the NORC's profile variables.

\section{Treatment}

Please block randomize treatment according to the seven-point party identification scale. Exactly half of each group should see these slides. The other half of each group should see the active control, below.

Democrats and Republicans are different types of people. What makes you similar to [own party]? Please write a few sentences.

[text box]

The "next" button will appear in 20 seconds.

\section{PAGE BREAK}

What makes you different from [other party]? Please write a few sentences.

[text box]

The "next" button will appear in 20 seconds.

\section{Active Control}

Display if treatment not displayed.

What is your favorite activity? [in-line text box]

What makes you different from people who enjoy this activity? Please write a few sentences.

[text box]

The "next" button will appear in 20 seconds.

\section{PAGE BREAK}

What is your favorite activity? [in-line text box]

What makes you different from people who enjoy this activity? Please write a few sentences. [text box] 
The "next" button will appear in 20 seconds.

\section{Party Identity Scale}

For the following questions, please fill in "Democrat" if the respondent is a Democrat or leans toward the Democrats. Please fill in "Republican" if the respondent is a Republican or leans towards the Republicans.

Do you agree or disagree with the following statements?-

\begin{tabular}{lcccc}
\hline & $\begin{array}{c}\text { Disagree } \\
\text { strongly }\end{array}$ & $\begin{array}{c}\text { Disagree } \\
\text { somewhat }\end{array}$ & $\begin{array}{c}\text { Agree } \\
\text { somewhat }\end{array}$ & $\begin{array}{c}\text { Agree } \\
\text { strongly }\end{array}$ \\
\hline $\begin{array}{l}\text { When I talk about [party]s, I say "we" rather } \\
\text { than "they." }\end{array}$ & 0 & $\circ$ & $\circ$ & $\circ$ \\
I have many qualities that are typical of & $\circ$ & $\circ$ & $\circ$ & $\circ$ \\
[party]s. & & & $\circ$ \\
When someone praises [party]s, it feels like a & $\circ$ & $\circ$ & $\circ$ & $\circ$ \\
personal compliment. & & & $\circ$ \\
I think of myself as a [party]. & $\circ$ & $\circ$ & $\circ$ \\
Being a [party] is important to me. & $\circ$ & $\circ$ & $\circ$ & $\circ$ \\
\hline
\end{tabular}

\section{Candidate Choice Instructions}

Your next task is to choose between pairs of candidates for Congress. There will be three total choices. On each page, the "next" button will appear after 20 seconds.

\section{Candidate Choices}

[Each respondent completed three candidate choice tasks. A screen shot appears in Figure B.8.] 
Figure B.8: Candidate choice screen shot, Study 2.

\section{Which candidate do you prefer?}

Jamal Gaines

\begin{tabular}{|c|c|}
\hline 40 years cid & 40 years old \\
\hline Business exccutove & Doctor \\
\hline Married, one child & Married, one child \\
\hline $\begin{array}{l}\text { Supports allowing Amencans to buy chesper prescription drugs from } \\
\text { Canada. }\end{array}$ & $\begin{array}{l}\text { Supports allowing Ammericans to buy cheaper prescription drugs from } \\
\text { Canodd. }\end{array}$ \\
\hline $\begin{array}{l}\text { During the last campaign, Gaines's saff collected blank absentee } \\
\text { ballots from voters and turned them in as votes. }\end{array}$ & $\begin{array}{l}\text { Proposed a plan to make sure absentee voters know never to give } \\
\qquad \text { their ballot to acyone else. }\end{array}$ \\
\hline Otamal Gaines & Oasmin Jefferson \\
\hline
\end{tabular}

\section{PREVIOUS CONTINUE}

Note: Aesthetic choices that differ from Study 1 were imposed by the NORC. 


\section{B.6 Candidate Choice Randomization for Study 2}

This section describes the candidate choice randomization scheme for Study 2.

Political party: Each candidate has the same political party as the respondent.

Name, race, and gender: Six names were randomly drawn from Table B.8. One was assigned to each candidate.

Age: For each choice task, draw two random integers between 35 and 65 with equal probability.

Profession: For each choice task, draw two of the following with equal probability:

- Served in the army

- Business executive

- Doctor

- Lawyer

- Farmer

- Police officer

- Political staffer

- Prosecutor

- Small business owner

- Teacher

Family: For each choice task, draw two of the following with equal probability:

- Married, no children $(\times 2)$

- Married, one child $(\times 2)$

- Married, two children $(\times 2)$

- Married, three children $(\times 2)$

- Married, four children

- Unmarried, no children $(\times 2)$

- Unmarried, one child

- Unmarried, two children

Policy positions: For each choice task, draw two of the following with equal probability:

- Supports simplifying the tax code so that everyone pays their fair share.

- Supports replacing individual income taxes with a value-added tax.

- Supports allowing Americans to buy cheaper prescription drugs from Canada.

- Supports laws to prevent companies from collecting personal data without permission. 
- Supports aggressive anti-trust enforcement against Amazon, Facebook, and Google.

- Supports letting illegal immigrants earn citizenship if tough enforcement measures come first.

- Supports increasing spending on infrastructure projects, including roads and bridges.

- Supports a constitutional amendment requiring Congress to balance the budget every year.

- Supports a constitutional amendment limiting members of Congress to two terms.

- Supports paying teachers more when their students do well on standardized tests.

Democracy positions: With equal probability, draw three rows from Table 1 in the main text, using only the "unfair action" and "reformer's response" columns. Assign one row to each choice. 


\section{Proofs}

\section{C.1 Fixed Baseline Assumption}

The fixed baseline assumption holds that in choices between two candidates generated by identical random assignment mechanisms,

$$
\mathbb{E}[Y \mid X=x]=0.5
$$

where just as in the main text, $Y \in\{0,1\}$ equals 1 if candidate 1 is chosen and 0 otherwise. $X$ can be any respondent characteristic or combination thereof.

Suppose that the respondent's choice $Y$ is based on some function of the candidates' attributes. Denote this function as $f\left(\mathbf{C}_{j}\right)$, where $\mathbf{C}_{j}$ contains all candidate attributes. In a choice between two candidates two candidates $J \in\{1,2\}$, the respondent chooses candidate 1 if

$$
f\left(\mathbf{C}_{1}\right)>f\left(\mathbf{C}_{2}\right)
$$

This is true by definition. Consider any function $f^{\prime}$. If a respondent chooses candidate 1 , but $f^{\prime}\left(\mathbf{C}_{1}\right)<f^{\prime}\left(\mathbf{C}_{2}\right)$, then $f^{\prime}$ cannot have been the function that determines the respondent's choice. This implies a restatement of (7),

$$
\begin{aligned}
\mathbb{E}[Y \mid X=x] & =\mathbb{E}\left[\mathbb{1}\left(f\left(\mathbf{C}_{1}\right)>f\left(\mathbf{C}_{2}\right)\right) \mid X=x\right] \\
& =\operatorname{Pr}\left[f\left(\mathbf{C}_{1}\right)>f\left(\mathbf{C}_{2}\right) \mid X=x\right]=0.5
\end{aligned}
$$

where $\mathbb{1}$ is the indicator function.

Now suppose that the candidates' attributes are drawn from identical distributions. This means that $\mathbf{C}_{1}$ and $\mathbf{C}_{2}$ are exchangeable (Hoff 2009, 27). Moreover, consider that by design, respondents must choose candidate 1 or 2 . From the laws of probability, it follows that

$$
\operatorname{Pr}\left[f\left(\mathbf{C}_{1}\right)>f\left(\mathbf{C}_{2}\right) \mid X=x\right]+\operatorname{Pr}\left[f\left(\mathbf{C}_{1}\right)<f\left(\mathbf{C}_{2}\right) \mid X=x\right]=1 .
$$

By (10) and exchangeability of $\mathbf{C}_{1}$ and $\mathbf{C}_{2}$, it must be that

$$
\operatorname{Pr}\left[f\left(\mathbf{C}_{1}\right)>f\left(\mathbf{C}_{2}\right) \mid X=x\right]=\operatorname{Pr}\left[f\left(\mathbf{C}_{1}\right)<f\left(\mathbf{C}_{2}\right) \mid X=x\right] .
$$

For suppose not. Because $f$ is the same, a difference between these quantities could only arise between differences in the possible realizations of $\mathbf{C}_{1}$ and $\mathbf{C}_{2}$, violating exchangeability.

It follows from (10) and (11) that

$$
\operatorname{Pr}\left[f\left(\mathbf{C}_{1}\right)>f\left(\mathbf{C}_{2}\right) \mid X=x\right]=0.5 .
$$

which by (9), is equivalent to (7). 


\section{C.2 Estimating Heterogeneous Effects with a Fixed Baseline}

The standard treatment by covariate model for estimating a linear approximation of heterogeneous effects is

$$
Y_{i}=\beta_{0}+\beta_{1} X_{i}+\beta_{2} Z_{i}+\beta_{3} X_{i} Z_{i}+\epsilon_{i}
$$

Define the control group as respondents for whom $Z_{i}=0$ and the treatment group as respondents for whom $Z_{i}=1$. It is well-known that if the control group's outcome is written as

$$
Y_{i}=\beta_{0}+\beta_{1} X_{i}+\epsilon_{i}
$$

and the treatment group's outcome is written as

$$
Y_{i}=\delta_{0}+\delta_{1} X_{i}+\epsilon_{i}
$$

then (13) can be rewritten as

$$
Y_{i}=\beta_{0}+\beta_{1} X_{i}+\left(\delta_{0}-\beta_{0}\right) Z_{i}+\left(\delta_{1}-\beta_{1}\right) X_{i} Z_{i}+\epsilon_{i}
$$

where

$$
\beta_{2}=\delta_{0}-\beta_{0}
$$

and

$$
\beta_{3}=\delta_{1}-\beta_{1}
$$

(see, e.g., Fox 2016; Wooldridge 2012).

Constant coefficients under the fixed baseline assumption.

Now consider (14). It is well-known that

$$
\beta_{0}=\mathbb{E}\left[Y_{i} \mid X=0\right]
$$

(see, e.g., Aronow and Miller 2019; Wooldridge 2012). From the proof of (7), we know that $E[Y \mid X=x]=0.5$. This means that

$$
\beta_{0}=0.5
$$

Moreover, it is also well-known that

$$
\beta_{1}=\frac{\operatorname{cov}(X, Y)}{\operatorname{var}(X)}=\frac{\mathbb{E}[X Y]-\mathbb{E}[X] \mathbb{E}[Y]}{\mathbb{E}\left[X^{2}\right]-\mathbb{E}[X]^{2}}
$$


(see, e.g., Aronow and Miller 2019; Wooldridge 2012). The first term in the denominator, $\mathbb{E}[X Y]$, can be rewritten as $\sum_{x} x \mathbb{E}[Y \mid X=x] \operatorname{Pr}(X=x)$. Again by (7), we know that $E[Y \mid X=x]$ a constant. This means that

$$
\begin{aligned}
\mathbb{E}[X Y] & =\sum_{x} x \mathbb{E}[Y \mid X=x] \operatorname{Pr}(X=x) \\
& =E[Y] \sum_{x} x \operatorname{Pr}(X=x) \\
& =\mathbb{E}[X] \mathbb{E}[Y]
\end{aligned}
$$

Substituting (22) into (21) sets the denominator equal to zero, in turn meaning that

$$
\beta_{1}=0
$$

Substituting (23) into (18) gives

$$
\beta_{3}=\delta_{1}-0=\delta_{1}
$$

Substituting (20) into (17) gives

$$
\beta_{2}=\delta_{0}-0.5
$$

Rewriting the heterogeneous effects.

We now have the ingredients necessary to estimate $\beta_{2}$ and $\beta_{3}$ using only the treatment group's data.

Substituting (20) and (24) into the expression for the treatment group's outcome, (15), gives

$$
Y_{i}=\delta_{0}+\beta_{3} X_{i}+\epsilon_{i}
$$

Subtracting 0.5 from both sides gives

$$
Y_{i}-0.5=\delta_{0}-0.5+\beta_{3} X_{i}+\epsilon_{i}
$$

Substituting (25) into (27) gives

$$
Y_{i}-0.5=\beta_{2}+\beta_{3} X_{i}+\epsilon_{i}
$$

In the main text, (28) is used to estimate $\beta_{2}$ and $\beta_{3}$ using only the treatment group's data under the fixed baseline assumption. 